\title{
Gender and Political Mobilization Online: Participation and Policy Success on a Global Petitioning Platform
}

\section{Citation}

Mellon, Jonathan, Hollie Russon Gilman, Fredrik M. Sjoberg, and Tiago Peixoto. "Gender and political mobilization online: Participation and policy success on a global petitioning platform." Ash Center Occasional Papers Series, Harvard University, Cambridge, MA, 2017.

\section{Published Version}

https://ash.harvard.edu/ash-publications

\section{Permanent link}

http://nrs.harvard.edu/urn-3:HUL.InstRepos:42367269

\section{Terms of Use}

This article was downloaded from Harvard University's DASH repository, and is made available under the terms and conditions applicable to Other Posted Material, as set forth at http:// nrs.harvard.edu/urn-3:HUL.InstRepos:dash.current.terms-of-use\#LAA

\section{Share Your Story}

The Harvard community has made this article openly available.

Please share how this access benefits you. Submit a story.

\section{Accessibility}




\title{
Ash Center Occasional Papers
}

Tony Saich, Series Editor

\section{Gender and Political Mobilization Online: Participation and Policy Success on a Global Petitioning Platiorm}

\author{
Jonathan Mellon, DPhil \\ Nuffield College, University of Oxford and The World Bank \\ Hollie Russon Gilman, PhD \\ School of International and Public Affairs, Columbia University \\ Fredrik M. Sjoberg, PhD \\ The World Bank \\ Tiago Peixoto, PhD \\ The World Bank
}

July 2017

Ash Center for Democratic Governance and Innovation Harvard Kennedy School 


\section{Ash Center Occasional Papers Series \\ Series Editor Tony Saich \\ Deputy Editor Jessica Engelman}

The Roy and Lila Ash Center for Democratic Governance and Innovation advances excellence and innovation in governance and public policy through research, education, and public discussion. The Ford Foundation is a founding donor of the Center. Additional information about the Ash Center is available at www.ash.harvard.edu.

This research paper is one in a series funded by the Ash Center for Democratic Governance and Innovation at Harvard University's John F. Kennedy School of Government. The views expressed in the Ash Center Occasional Papers Series are those of the author(s) and do not necessarily reflect those of the John F. Kennedy School of Government or of Harvard University. The papers in this series are intended to elicit feedback and to encourage debate on important public policy challenges.

This paper is copyrighted by the author(s). It cannot be reproduced or reused without permission. 
Ash Center Occasional Papers

Tony Saich, Series Editor

\section{Gender and Political Mobilization Online: Participation and Policy Success on a Global Petitioning Platform}

Jonathan Mellon, DPhil

Nuffield College, University of Oxford and The World Bank

Hollie Russon Gilman, PhD

School of International and Public Affairs, Columbia University

Fredrik M. Sjoberg, PhD

The World Bank

Tiago Peixoto, $\mathrm{PhD}$

The World Bank

July 2017

Ash Center for Democratic Governance and Innovation

Harvard Kennedy School 



\section{Letter from the Editor}

The Roy and Lila Ash Center for Democratic Governance and Innovation advances excellence and innovation in governance and public policy through research, education, and public discussion. Three major programs support our mission:

- The Program on Democratic Governance researches those practices that resolve urgent social problems in developed and developing societies.

- The Innovations in Government Program recognizes and promotes creative and effective problem-solving by governments and citizens.

- The Rajawali Foundation Institute for Asia promotes research and training on Asia to disseminate best practices and improve public policy.

Our Occasional Papers series highlights new research that we hope will engage our readers and prompt an energetic exchange of ideas in the public policy community.

The growing access to digital technologies has been considered by democratic scholars and practitioners as a unique opportunity to promote participatory governance. Yet, if the last two decades is the period in which connectivity has increased exponentially, it is also the moment in recent history that democratic growth has stalled and civic spaces have shrunk. While the full potential of "civic technologies" remains largely unfulfilled, understanding the extent to which they may further democratic goals is more pressing than ever.

This is precisely the task undertaken in this original and methodologically innovative research. The authors examine online petitions which, albeit understudied, are one of the fastest growing types of political participation across the globe. Drawing from an impressive dataset of 3.9 million signers of online petitions from 132 countries, the authors assess the extent to which online participation replicates or changes the gaps commonly found in offline participation, not only with regards to who participates (and how), but also with regards to which petitions are more likely to be successful. The findings, at times counterintuitive, provide several insights for democracy scholars and practitioners alike.

The authors hope this research will contribute to the larger conversation on the need of citizen participation beyond electoral cycles, and the role that technology can play in addressing both new and persisting challenges to democratic inclusiveness.

You may find all of the Ash Center's Occasional Papers online at ash.harvard.edu.

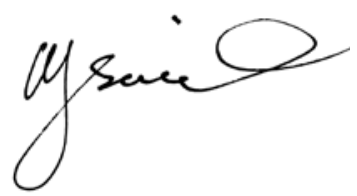

Tony Saich, Series Editor and Director

Ash Center for Democratic Governance and Innovation Harvard Kennedy School 



\section{Acknowledgments}

The authors would like to thank those who contributed with their comments and support at various stages of this work, including Archon Fung (Harvard University), Tim Glynn-Burke (Harvard University), Jessica Engelman (Harvard University), Daniel Harsha (Harvard University), Amy Chamberlain (George Washington University / The World Bank), Joshua Kalla (University of California, Berkeley), Michael Biggs (University of Oxford), Kate DeMoss (Tulane University), Claire Davanne (The World Bank), Patrick English (The University of Manchester), Zahid Hasnain (The World Bank), as well as discussants and participants present at the Midwest Political Science Association Conference, and at the Impact of Civic Technologies Conference (TICTec).

The authors would also like to note that the views expressed in this paper are those of the authors and do not necessarily reflect those of the institutions with which the authors are affiliated, past or present. 



\section{Contents}

Abstract $\ldots \ldots \ldots \ldots \ldots \ldots \ldots \ldots \ldots \ldots \ldots \ldots \ldots \ldots \ldots \ldots \ldots \ldots$

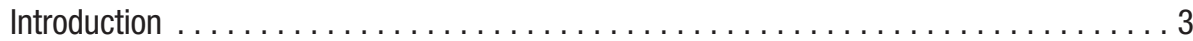

Background and Theoretical Framework $\ldots \ldots \ldots \ldots \ldots \ldots \ldots \ldots \ldots \ldots$

Participation $\ldots \ldots \ldots \ldots \ldots \ldots \ldots \ldots \ldots \ldots \ldots \ldots \ldots \ldots \ldots \ldots \ldots$

Descriptive Success $\ldots \ldots \ldots \ldots \ldots \ldots \ldots \ldots \ldots \ldots \ldots$

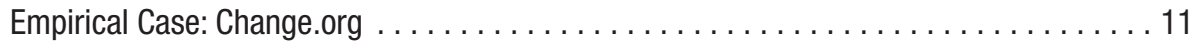

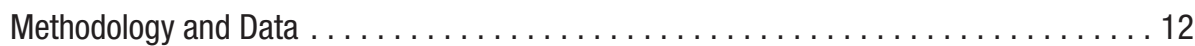

Gender Coding . . . . . . . . . . . . . . . . . . . . . 13

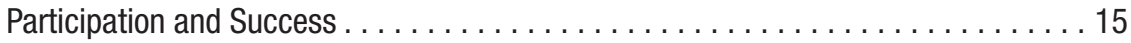

Participation Across Countries. . . . . . . . . . . . . . . . . . . 17

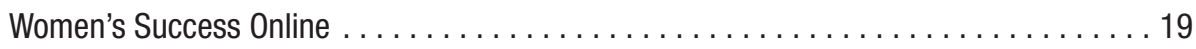

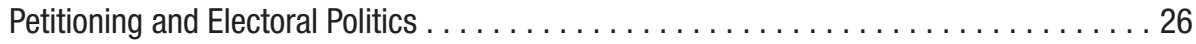

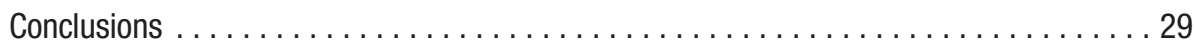

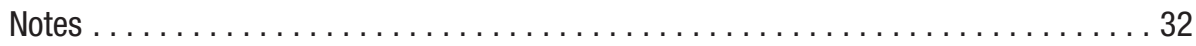

References .............................. 34

Appendix A: Change.org Petition Submission. . . . . . . . . . . . . . . . 39

Appendix B: Steps to Declare Victory. . . . . . . . . . . . . . . . . 44

Appendix C: Steps to Validate Victory $\ldots \ldots \ldots \ldots \ldots \ldots \ldots \ldots \ldots \ldots \ldots$

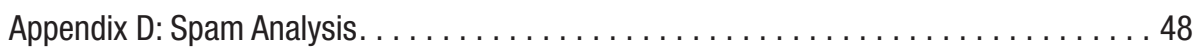

Appendix E: Simulation Analysis $\ldots \ldots \ldots \ldots \ldots \ldots \ldots \ldots \ldots \ldots \ldots \ldots \ldots$ 



\section{Abstract}

As political life moves online, it is important to know whether online political participation excludes certain groups. Using a dataset of 3.9 million signers of online petitions in 132 countries, we examine the descriptive success (number of successful petitions) and substantive success (topic of successful petitions) of women and men. Women's participation is higher than expected in the 'thin' action of petition signing, but consistently lower in the 'thick' action of petition creation. We do not find a link between lower female thick participation and female descriptive success. In terms of substantive success, we find successful petitions reflect female users' priorities more closely than men's, independent of the petition initiator's gender. These results hold both platform-wide and within most countries in the dataset. We show that these results occur due to the low level of petition success $(1.2 \%)$ on the platform, which increases the importance of thin forms of participation.

Keywords: gender representation, political participation, online petitions, descriptive representation and substantive representation, descriptive success and substantive success. 



\section{Introduction}

The Internet has opened up new forms of political participation. One of the most common is online petitioning. Despite the huge scale of these platforms, ${ }^{1}$ little is known about how different demographic groups participate on them or whose interests these petitions reflect. Scholars have raised concerns about whether online political participation may exclude certain groups from politics (Schlozman, Verba, and Brady 2010) and who participates online (for discussion see Norris 2001) due to differential access to the Internet (Wilhelm 2000), the technical skills required to participate online (Best and Krueger 2005), and the potential for rancorous debate and online harassment (Stromer-Galley 2002). Conversely, expressing political views on the Internet may be more convenient and less intimidating (Stromer-Galley 2002). If so, online participation could be more inclusive than traditional forms of political engagement.

It is therefore an open question whether online participation will tend to replicate, exacerbate, or change the participatory and representational gaps in offline participation. Women in advanced industrial democracies are more likely than men to engage in thin forms of participation such as voting yet less likely to engage in thick forms such as donating money, running for office, or taking part in political deliberations (Karpowitz, Mendelberg, and Shaker 2012; Wolak 2014; Verba, Schlozman, and Brady 1995). Lower thick participation means that fewer women are elected to legislatures, which appears to reduce the fit between policy and women's interests (Wängnerud 2009).

In this article we focus on the participation and success of women on Change.org, an online petition website allowing anyone worldwide to create and sign petitions. More than 177 million people across 196 countries have used the platform. ${ }^{2}$ We have little information about online inclusiveness on a global scale (although, see Marien, Hooghe, and Quintelier 2010) as existing studies of online participation use single-country case studies (e.g., Albrecht 2006; Anduiza, Gallego, and Cantijoch 2010; di Gennaro and Dutton 2006; Hagemann 2002; Jankowski and van Selm 2001; Jensen 2003; Johnson and Kaye 2003; Schlozman, Verba, and Brady 2010).

We find women are well represented in signing petitions (thin participation) but are underrepresented in petition creation (thick participation). Despite women's underrepresentation in petition creation, the majority of successful petitions are created by women (descriptive success) and the issues 
covered by successful petitions tend to be those favored by female petition signers and creators (substantive success). There are three reasons for the disconnect between thick participation and success: 1) female-created petitions are signed at higher rates by both men and women; (2) women sign female-created petitions at an even higher rate (partially because of issue congruence between female creators and signers); and (3) since women sign more petitions than men in general, women's thin participation has a stronger effect on which petitions receive the most signatures. These patterns also hold within most individual countries in the dataset, showing that these mechanisms are widely applicable.

This paper begins by discussing the existing work on female participation and success, and shows how we would expect these patterns to differ in the context of online petitioning. We then describe the case of Change.org and the methodology and data we use to address the research questions. We then present our empirical findings and conclude by discussing their implications for understanding gender participation and success both online and more generally.

\section{Background and Theoretical Framework}

In this section we set out how we conceptualize different forms of group participation and success across different modes of politics. We compare these concepts in terms of electoral politics and petitioning, but the categories we define can be applied to many modes of politics. In the case of participation, the analogy between electoral politics and petitioning is relatively straightforward. Within participation, we distinguish between relatively low-cost, thin participation that focuses on choosing between existing options, and thick participation which requires a higher investment of time (Leigninger 2014) and helps to define the choices that can be made. ${ }^{3}$

In the case of electoral politics, this distinction is best described in terms of voting (thin) and running for office (thick). In the case of petitions, we distinguish between signing petitions (thin) and creating petitions (thick). In both cases, the thick participation determines the choice set (candidates or petitions, respectively) for thin participation. In the case of petitions, we are interested in whether there is a gender divide in either of these forms of participation.

In electoral politics, success for a group is generally defined either in terms of descriptive representation (group members being elected) or substantive 
representation (implementing the interests of the group) (Pitkin 1967). While the language of representation is not applicable to petitioning, the distinction between descriptive and substantive forms of success has analogues in petitioning.

We define descriptive success as members of a group being successful in their thick participation. Hence, in electoral politics, descriptive success means women who run for office (thick participation) succeed in being elected. In the case of petitioning, descriptive success means women who create petitions (thick participation) succeed in having their petitions' demands granted. While some thick participation by a group is a necessary condition for the group to have descriptive success, inequalities in thick participation do not necessarily lead to the same inequalities in descriptive success. As an (unrealistic) example, if 30 women and 20 men ran for office in 11 districts, women would be overrepresented in terms of thick participation. However, it would still be possible for women to fail to have descriptive success if all 11 districts were won by men.

We define substantive success as the reflection of preferences of group members in policy. Importantly, in both electoral politics and petitioning, descriptive success does not guarantee a group's substantive success. This can be either because the group members who are successful in their thick participation (politicians or petition creators) do not share the same preferences as the group more generally or because other aspects of the system stop group members from translating their agenda into policy. For instance, in electoral politics, women may be elected from a party with a platform that is incongruent with the preferences of most women. In the case of petitioning, women may be successful without their petitions necessarily representing the interests of women on the platform in general. The link between descriptive and substantive success is an empirical question and one that can vary across different contexts.

Even without substantive success, descriptive success can be valuable for a group. Group members being descriptively successful can increase the perceived legitimacy of the policy process and provide role models. These arguments could also apply to petitioning. Media coverage of petitions often focuses on the creator of the position and their fight for justice, ${ }^{4}$ which could have symbolic benefits for group members. Nonetheless, these symbolic benefits are less important in the context of petitions, as creating a successful petition only directly generates a single instance of political success. By 
contrast, electing group members to public office gives a group a sustained voice in the policy process and public sphere.

Table 1 summarizes what actions and outcomes are considered thin participation, thick participation, descriptive success, and substantive success in the electoral and petitioning modes.

Table 1: Stages of Participation and Success in Electoral Politics and Petitioning

\begin{tabular}{|l|l|l|l|l|}
\hline & \multicolumn{2}{|c|}{ Participation } & & \multicolumn{2}{c|}{ Success } \\
\hline Mode & Thin & Thick & Descriptive & Substantive \\
\hline Electoral & Women voting & Women running for office & $\begin{array}{l}\text { Women elected } \\
\text { (descriptive representation) }\end{array}$ & $\begin{array}{l}\text { Women's preferences represented in policy } \\
\text { (substantive representation) }\end{array}$ \\
\hline Petitioning & $\begin{array}{l}\text { Women signing } \\
\text { petitions }\end{array}$ & Women creating petitions & $\begin{array}{l}\text { Petitions created by women } \\
\text { are successful }\end{array}$ & $\begin{array}{l}\text { Women's interests represented in policy as the } \\
\text { result of government response to the petition }\end{array}$ \\
\hline
\end{tabular}

The following sections explain these categories in more detail, summarizes the literature's findings around electoral democracy, and outlines how we might expect online petitioning to differ in terms of each form of participation and success.

\section{Participation}

Participation focuses on the inputs to a political process. The distinction between thin and thick is particularly important for understanding gender inequalities in political actions as women are more likely to take some thin actions such as voting but less likely to take thicker actions than men. In the current study, we separately consider gender differences among creators of online petitions (thick participation) and signers of those petitions (thin participation).

Women in advanced industrial democracies are more likely than men to engage in thin forms of participation such as voting yet less likely to engage in thick forms such as donating money, running for office, or taking part in political deliberations (Karpowitz, Mendelberg, and Shaker 2012; Wolak 2014; Verba, Schlozman, and Brady 1995).

Women's level of thin participation in electoral politics varies across countries and time. Women vote at consistently lower rates than men in certain countries, including Switzerland (Engeli, Ballmer-Cao, and Giugni 2006), 
whereas in other countries, such as Canada, there is no consistent difference between the genders (Blais, Gidengil, and Nevitte 2004). In Britain and the United States, turnout was lower for women until the 1970s but this gap disappeared (Childs 2004) or even reversed in recent elections (Norris 1999; Leighley and Nagler 2013). Overall, female electoral thin participation appears robust in recent years.

Online thin participation has been studied in a number of previous contexts including e-petitions (Dalton, Van Sickle, and Weldon 2009), reporting of local problems (Sjoberg, Mellon, and Peixoto 2017; Fox and Peixoto 2016), and voting for budget priorities (Spada et al. 2016). Online thin participation can enable participation at a massive scale by reducing participation costs (for discussion, see Nabatchi and Leighninger 2015, 211), including for new participants (Fung, Russon Gilman, and Shkabatur 2013).

Findings from a survey in Spain show a significant gender gap in online participation (Vicente and Novo 2014) that remains even among women who are online. Previous research on women's thin participation in the petitioning process finds women are well represented in petition signing. For instance, in Australia, signing online and offline petitions are two of the few political behaviors women undertake more than men (Sheppard 2015).

Women are underrepresented in thicker forms of political participation such as running for office (Costantini 1990), donating money for political advocacy (Verba, Schlozman, and Brady 1995), or taking part in deliberations (Karpowitz, Mendelberg, and Shaker 2012; Wolak 2014). Two broad explanations exist about why women are less likely to run for legislative office: gatekeeper explanations and supply-side explanations. Gatekeeper explanations argue potential female candidates are discouraged from seeking office by political elites. To be successful, candidates must depend on the support of party and interest group leaders, donors, volunteers, and activists. Without the support of gatekeepers, many women choose not to run for office (Burrell 1993; Conway 2001; Niven 1998; Norris and Lovenduski 1995). Supply-side explanations include gaps in political ambition between men and women (Fox and Lawless 2014), gender norms discouraging highly qualified women from political careers (Lawless and Fox 2005, 2010), and the uneven distribution of various qualifications and resources that are prerequisites for serving in office (Burns, Schlozman, and Verba 2001; Chhibber 2002; Corrin 1992; Rahat and Hazan 2001). 
Previous studies of thicker forms of participation online have generally found that women are underrepresented. For instance, Albrecht (2006) shows that online debates have a more extreme gender gap than would be implied by the gender digital divide. This pattern also appears to hold in non-political thick forms of participation. Marom, Robb, and Sade (2016) find that women make up $35 \%$ of project leaders and $44 \%$ of investors on Kickstarter.

Conditional on being a petition platform user (which requires Internet access), there are no gatekeepers stopping women from thicker forms of online participation. However, supply-side issues such as political ambitions and gender norms may still apply to women creating online petitions. Online petitioning provides a useful test case for understanding the extent of women's underrepresentation in thicker forms of political activity. In a study of 250 creators of e-petitions to the German parliament, Lindner and Riehm (2011) found the share of women was even lower than among offline petitioners.

\section{Descriptive Success}

Studies of representative democracy have focused on both descriptive and substantive forms of group success (note we use the term success rather than representation in this article, but most previous studies we refer to use representation). Descriptive success focuses on whether the people generating policy are representative of groups in society. We define descriptive success in petitioning in terms of the gender of the creators of successful petitions. That is, women are more descriptively successful if a higher proportion of successful petitions are created by women.

Previous studies have found women in most countries are less descriptively successful than men (Paxton 1997) in national legislatures. Most evidence suggests this underrepresentation is primarily an issue of thick participation (Hedlund et al. 1979; Zipp and Plutzer 1985; Smith and Fox 2001; Brians 2005); that is, women choose not to run for office (for the reasons outlined in the previous section).

This mechanism could also apply to online petitioning if women are less willing to create petitions. However, the importance of thick participation may also be different between the electoral and petitioning contexts. In majoritarian systems, if no woman is a candidate for a locally competitive party, then there is no chance of descriptive female success in that district. By contrast, in the context of online petitioning, there is a huge supply of 
petitions that could be signed and only a small proportion that succeed. Therefore, even if women were underrepresented among petition creators, it does not follow that they will automatically be underrepresented among successful petition creators, as there are still many times more female-created petitions than successful petitions, even if women are underrepresented compared with men in thick participation.

Some studies suggest female candidates benefit in electoral politics from higher crossover voting by women without losing an equivalent number of male voters (Hedlund et al. 1979; Zipp and Plutzer 1985; Smith and Fox 2001; Brians 2005), although these results vary across studies and often find small effects. It is not clear how much we should expect female thin participation (petition signing) to affect descriptive success. The identity of the petition creator is prominently displayed with a photo and name at the top of the petition page, so homophilous signing would be straightforward. Additionally, if women tend to create and sign petitions on similar topics, we would expect more gender homophily in signing, as a byproduct of similar policy preferences. We therefore expect thin participation by women in online petitioning to increase female descriptive success on the platform.

We do not aim to solve the conceptual debate ${ }^{5}$ over what it means for women (or anyone else) to be successful in promoting their interests. Instead, we take a narrower approach where women are substantively successful if the policy outputs of a process resemble the preferences of the women who participate. This does not account for false consciousness or whether the interests of women in general differ from those on the platform. However, it does reflect the extent to which women get the policy outputs they want.

In order to empirically examine women's substantive success, men and women must have different policy preferences (otherwise there is no way to tell whose interests are better represented). Previous research has found substantial gender differences in issue preferences between men and women (Lien 1998; Whitehead and Blankenship 2000; Shapiro and Mahajan 1986; Inglehart and Norris 2000; Beutel and Marini 1995). We potentially expect smaller differences in policy preferences between men and women in the context of online petitioning as petitioning platforms such as Change.org have tended to focus on liberal issues (although not exclusively), perhaps reducing the differences between male and female preferences due to self-selection onto the platform on the basis of ideology. However, previous research shows gender differences on policies persisting 
even after controlling for political party, so we expect there will be a reasonable degree of remaining variation in preferences and relative importance given to issues by men and women.

Pitkin (1967) argued that the similar experiences of subgroup members lead to a convergence in preferred outcomes between representatives and the subgroup (see Bettes 2015 for discussion). Since then, many scholars have raised the normative argument for higher levels of women in government to promote women's policy interests (Phillips 1998; Mansbridge 1999). However, as we discuss above, descriptive success for women does not automatically guarantee their substantive success (Celis et al. 2008) (cf. female anti-suffrage campaigners in the United States [Schreiber 2008]). Several studies find female legislators promote different interests than their male counterparts (for a review, see Wängnerud 2009) and are more likely to discuss, advance, and pass legislation relating to women's rights, social welfare, and public goods (Chattopadhyay and Duflo 2004; Pearson and Dancey 2011; Swers 2002, 2013). Swers (2013) finds women in the US Congress shift the conversation to focus more on policies which benefit women, for example prosecuting violence against women or increasing paid leave. Xydias (2007) examines gender quotas in Germany and finds women speak on and engage more substantively in women's issues and that the presence of a gender quota enhances attention to these issues. Scholars have also found evidence for a link between descriptive success in non-legislative roles (such as social movements and government bureaus) and substantive success (Weldon 2002).

Other studies argue that the link is more contingent, depending on institutions and norms (Franceschet and Piscopo 2008; Childs and Krook 2009), and many are skeptical about the automatic link between descriptive and substantive success (Childs 2004; Dodson 2006; Schwindt-Bayer 2006), positing that women can share a female perspective independent of, and not reliant on, any essential female identity (Young 2000).

These arguments are also applicable to online petitioning. If women are descriptively unsuccessful in online petitioning, it is possible that the policy outputs of the process might still resemble the preferences of women if successful male-created petitions are in line with female preferences and vice versa. However, if female-created petitions are more aligned with female preferences, the link between female descriptive and substantive success is likely to be present. 
Another factor that could potentially affect substantive success is the level of thin participation by women. In countries where male and female voters have different preferences (such as the United States) there is some evidence that the level of female participation affects the outcomes of elections and, therefore, policy outcomes (Abendschön and Steinmetz 2014).

One important difference between petitioning and representative democracy is that representative democracy is an indirect form of policy voting. The best a voter can hope to manage in representative democracy is choosing the candidate or party whose bundle of issue positions is closest to theirs, weighted by issue importance and competence (actual voting behavior is usually less optimal than this and includes strategic tradeoffs). Petitions (as with direct democracy) directly translate a person's preferences into a signature supporting a particular outcome. Given that platforms like Change.org host many petitions a user could sign, users are presented with a much more disaggregated set of choices than in an election.

Previous work on the Downing Street E-petitions platform found that successful petitions tend to have more signatures (Wright 2012). Consequently, we assume petition success in terms of policy will be at least partially predicted by the level of mobilization (number of signatures) around that petition. The number of signatures could have a direct effect of bolstering a petition's perceived legitimacy and acts as a proxy for the full level of mobilization around an issue. Based on these mechanisms, we predict a strong link between thin participation by women and female substantive success.

\section{Empirical Case: Change.org}

Change.org is a website that enables people to both start and sign a petition. Joining Change.org and creating a petition are free. Participants use a structured form to 1) identify the short title for their petition; 2) choose a decision maker; and 3) explain the problem to be solved. Petition creators can designate a specific number of users they want to sign their petition. Users can browse existing petitions to sign someone else's petition or use a search function to look for petitions on specific issues.

When someone is trying to promote a specific petition, they receive a customized URL to share. Linked to these pages are social media updates about 
the petition from Twitter and an area for public-facing comments. There is a visual indicator of petition signers and links to promote specific organizations. Signers need to provide their name and address and accept Change. org's terms of service and privacy policy in order to sign. Signers have the option of displaying their name and reason for signing. Change.org provides advice for maximizing a petition's impact, including leveraging social media, creating a short video, hosting in-person organizing events, and reaching out to existing networks and listservs. Change.org offers the option to pair petition creators with a coach.

Change.org is a certified "B corporation" and social enterprise platform. More than 100,000 corporations and organizations pay Change.org to host and promote their petitions. Online petitioning has the potential to reduce barriers to entry for reaching decision makers, particularly for traditionally excluded demographic groups. There are numerous online petition sites for advocacy, including MoveOn.org Petitions, Causes.com, Avaaz.org, amongst others. Change.org has the most visibility, staffing, and reach.

The petitions can be aimed at any decision maker in the public or private sector and at entities ranging from international organizations to local firms. One such successful petition was started in response to the rape of a six-year-old girl in a Bangalorean school. Another mother in the area started a petition asking the Karnataka state government to set guidelines for child safety in schools. After receiving 155,580 signatures, the education minister issued a list of 70 guidelines schools in the state should follow to increase the safety of children including installing CCTV and conducting background checks on staff.?

While Change.org does not have an explicit political stance, it is used most heavily by liberal campaigners and causes and less so by right-wing and socially conservative campaigners. This means that our analysis is primarily focused on the descriptive and substantive success of women in online participation focused on progressive causes. The participation and success of citizens championing more conservative causes could be studied in future work on equivalent conservative focused sites such as standunited.org.

\section{Methodology and Data}

Using Change.org's public API, ${ }^{8}$ we sampled the details of 3,945,701 users. Each new user in Change.org's system is given a sequential ID number, so it 
is possible to randomly sample users simply by choosing a random number from a uniform sequence from 1 to the most recent user. The information includes the petitions each user has signed, their date of joining Change. org, name, and location (down to city level). In total, there are users from 253 countries and territories listed within the dataset. There are 1,673,025 sampled users (42.4\%)from the United States, followed by 377,026 (9.6\%) from Spain and 233,003 (5.9\%) from the United Kingdom. There are also substantial numbers of users from developing countries including Brazil $(94,049)$, Turkey $(62,880)$, Mexico $(56,680)$, and India $(55,103) .{ }^{9}$ Users agree to display their names publicly as part of Change.org's terms and conditions, although they can hide their signatures if they choose.

We also sampled details of all petitions including the number of signatures, the category of the petition, and whether the petition was successful in achieving its stated goal. We restrict the samples of petitions and users as follows. We restrict the petition sample to petitions that have either been closed or declared a victory, so the outcome is known. Additionally, we include only those petitions identified as created by a single individual (not those attributed to entire organizations). Finally, we exclude spam petitions based on an iterative flagging process (see Appendix D). We restrict the sample of users to those who sign at least one petition in the remaining sample.

\section{Gender Coding}

Change.org does not include self-reported information on users' gender identities. Consequently, we rely on other clues about users' most likely gender identity. In particular, we make use of the strong empirical link between given names and gender. Since the Change.org data includes the names of users who publicly sign petitions, we use this information to infer their likely gender. Variants of this technique have been used in previous studies (Fisher et al. 1998; Sloan et al. 2013; Ausserhofer and Maireder 2013; Mislove et al. 2011).

We code the likely gender of Change.org users based on two sources: US Social Security Administration (SSA) records and the proprietary gender coding service genderize.io. Both approaches code gender based on first names.

For the Social Security database gender coding, we combine two sources of data. We take the name frequencies from the SSA baby names database that provides frequencies for each first name, for each gender, in each year going back to 1880 . We adjust these name frequencies using Centers for Disease Control and Prevention life tables ${ }^{10}$ showing what proportion of 
men and women born in each year are alive today. The adjusted results give frequencies for each name for men and women. We then transform these frequencies into proportions telling us what proportion of people with each name (alive today) is male or female. We then assign individual users a probability of being each gender based on how likely their name is to be male or female. This approach will be the most effective within the US as the names data are derived from US records. There are several difficulties with coding gender from names. The first difficulty is that many names in non-Latin scripts (e.g., Russian and Chinese) are not listed in US databases. To account for this, we use transliteration software to convert these names into Latin script, allowing them to be matched to names in the SSA database. Another difficulty is that some names were not present in the US names database. To tackle this problem, we manually coded the gender for names that appear more than 200 times in the dataset and did not appear in the US data. We manually coded these names by searching the Internet for people with the first name and assessing whether it was primarily given to men or women.

To improve the international coverage and cross-check the SSA results, we also use the proprietary genderize.io database. The genderize.io database is built from social media profile data from different countries, which allows coding to be localized to particular countries. At the time of analysis (5th October 2016), genderize.io described its database as containing 216,286 distinct names in 79 countries and 89 languages. We first attempt to code each case using the localized coder in genderize.io. If localized coding is not available, we use global coding (taking advantage of names data across the world rather than just in one particular country).

Both approaches have good coverage of Change.org users. Overall, genderize.io has better coverage of Change.org user's names (93.8\%) than the SSA database $(87.5 \%)$. However, the combined coverage is better still, with $94.8 \%$ of users covered by at least one of the two methods. The coverage for petition creators is similar; we were able to code $90.4 \%$ of names with at least one of the methods.

Across the 1,927,505 users whose first name was matched in both the genderize.io and Social Security databases, there is a near-perfect correlation between the gender probabilities assigned by both methods $(r=0.97)$. Similarly, there is a strong correlation between the probability of a petition creator being male according to genderize.io and the SSA database $(r=0.97)$. 
For users we categorize as likely male or likely female ( $>90 \%$ probability), the two approaches have $99.4 \%$ agreement. Given the high level of coverage and agreement for the two methods, we are confident our gender coding is not a major source of error in our analysis. Although some users have gender-neutral names, the gender probabilities for Change.org are bimodal: the vast majority of names are almost exclusively male or female. Just 3.7\% of users and $5.2 \%$ of petition creators cannot be assigned a gender with more than $90 \%$ certainty. We use gender probabilities to create a binary gender indicator for users with greater than $90 \%$ certainty of one gender or the other.

\section{Participation and Success}

We measure thin participation by analyzing the proportion of Change.org users who are coded as female and thick participation by looking at the proportion of Change.org petitions created by users coded as women. We measure descriptive success in terms of the proportion of successful petitions created by women. Success is self-reported by petition creators using the dialog button shown in Figure 1. ${ }^{11}$

Figure 1: Victory Button on the Change.Org Petition Dashboard

\section{Manage petition}

Did you come to an agreement with your decision maker? Declare your petition a victory and let your supporters know how they helped make it happen.

Declare victory Close petition

The text around the victory button refers back to the original petition and an agreement with the decision maker. This prompt should exclude cases where the petition's goal is achieved incidentally and only includes cases where the petition maker at least feels they played a role in achieving the desired outcome of the petition. Nonetheless, we should consider petition creators' incentives to overstate their success and personal impact, to acknowledge the possibility of over-reporting. To check whether the successes that petition creators claim actually occurred, we manually coded 296 randomly sampled successful petitions. Eighty-one percent of the successes claimed are either 
confirmed externally or are coded as highly plausible. ${ }^{12}$ We also manually coded whether the success these petitions claim to achieve satisfies the petition's original demands. The mean score of successful petitions was 8.8 on a 0 to 10 scale measuring the extent to which the petition achieved its original goal. See Appendix C for more detail on the validation process.

\section{Measuring Substantive Success}

We compare the issue agenda at different stages (petition creation, signing, and success) to the preferences of male and female petition creators in order to understand whether gendered issue preferences translate into outcomes of the petitioning process.

We define policy agendas as the topical distribution of all petitions on Change. org within a certain subset. So the female creator agenda is the distribution of petition topics across female-created petitions and the male signer agenda is the distribution of petition topics across petitions weighted by the number of men signing each petition. The substantive agenda (what is actually implemented) is measured as the topic distribution across all successful petitions.

We primarily use petition creators as our benchmarks of female and male preferences on the Change.org platform because petition creation is the first step in the process. If we instead used signatures, the apparent agenda could be skewed by the availability of petitions to sign on different topics (in fact this mechanism is the primary way that agenda setting by petition creators could have an effect on the outcomes of the process). However, we look at male and female signature agendas as secondary measures of agenda match.

We compare the issue agenda at each stage by comparing the percentage of petitions or signatures in each of the issue categories using the following formula:

$$
100-\frac{\sum_{c \in M}\left|x_{c 1}-x_{c 2}\right|}{2}
$$

where $x_{n c}$ is the proportion of petitions/signatures in category $c$ for agenda $n$ and $M$ is the set of 14 possible categories. The summation is divided by two so the range of the difference score goes from 100 (exactly the same agenda) to 0 (maximally different agenda). 


\section{Participation Across Countries}

This section presents results on women's participation in terms of petition signing (thin participation) and petition creation (thick participation). To look at thin participation, we first examine the gender balance in petition signing. Across all Change.org users in our sample, $57.3 \%$ are coded as female, showing Change.org is very inclusive of women at the signing stage. This result is partially driven by the high proportion of Change.org users located in the United States, where $62.1 \%$ of users are female. Averaging across the 132 countries in the sample with more than 100 users, the gender breakdown is more even, with an average of $47.3 \%$ of female users.

Figure 2 shows the gender balance in Change.org signing plotted against the gender balance in offline petition signing (as measured on the World Values Survey). The red line is the identity line where the gender balance in online petitions is the same as the gender balance in all petitions. Countries above the line have higher levels of female participation online than offline, and countries below the line have lower levels of female participation online than offline. The countries in our sample are evenly distributed around the identity line, indicating that the gender inclusiveness of online petitions is not systematically higher or lower than offline petitions.

Figure 2: Proportion of Women in Online Petitions Against Proportion of Women in Offline Petitions

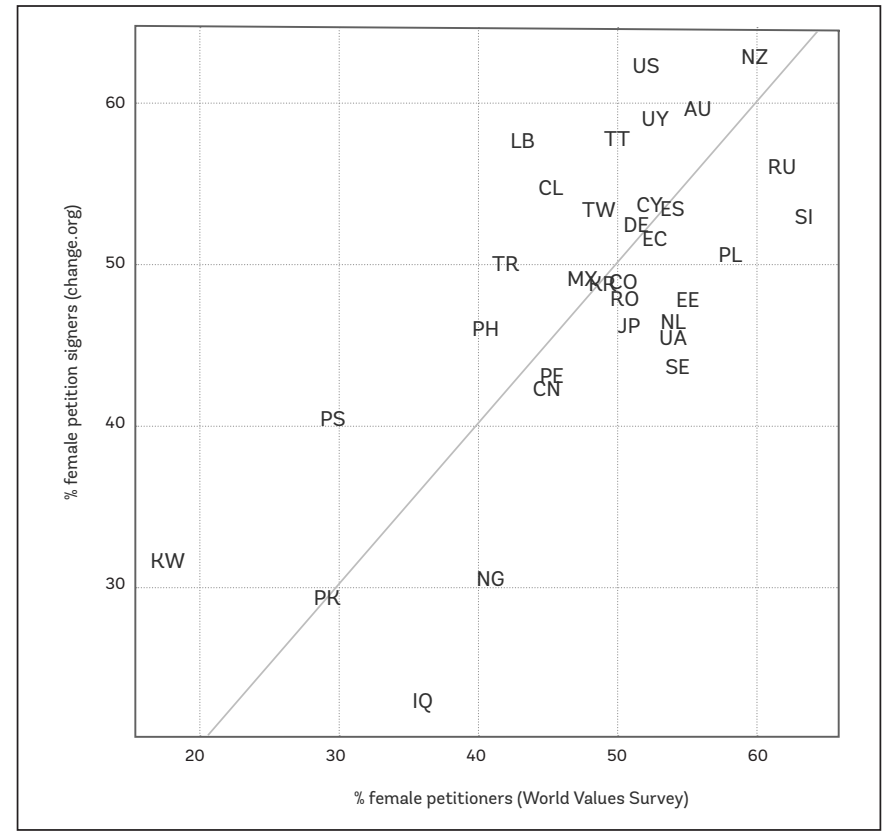

* Note: Gray line indicates identity line. 
While women participate at higher rates in terms of signing, our results show women participate at much lower levels in terms of petition creation. Over half $(56 \%)$ of petitions are created by men $(n=299,832)$, suggesting there could be an agenda-setting bias.

This result is remarkably consistent across countries. Figure 3 shows the percentage of female Change.org petition creators plotted against the proportion of female petition creators for the 76 countries in the sample with more than 100 petition signers and creators to code. In all but five countries, a higher proportion of petition creators are men than the proportion of petition signers in that country. In other words, male Change.org users disproportionately create petitions across the world. This finding fits with the patterns described in representative democracy, where women vote at relatively high rates but run for political office at much lower rates than men. Since women and men have different policy priorities (as we shall see in the next section) the lower thick participation of women raises serious questions of whether women will be substantially successful on the platform (in addition to the descriptive success problem).

Figure 3: Proportion of Online Petitions Created by Women Against Proportion of Change.org Users Who Are Women in Each Country

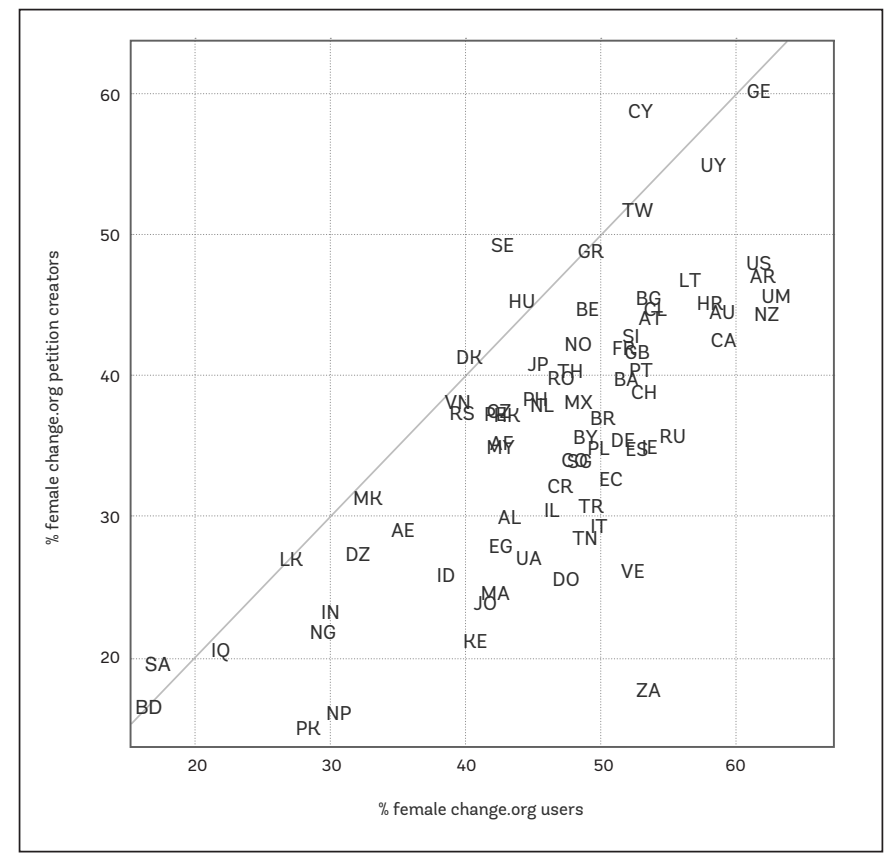

* Note: Gray line indicates identity line. 


\section{Women's Success Online}

This section describes the extent to which men and women are descriptively and substantively successful on Change.org. In descriptive terms we focus on the extent to which female or male petitions succeed in their goals. In substantive success we focus on the extent to which men and women's preferences are implemented through the Change.org platform. The previous section shows different results for participation when looking at thin and thick actions in online petitioning. It is therefore not clear whether we would expect the greater agenda-setting power of men's thick participation or women's higher levels of overall mobilization (in terms of thin participation) to be more important to the outcomes of the petitioning process. We define the policy outcomes of the Change.org platform in terms of the issues of successful petitions.

Although participation is important in itself, it is also important to focus on the output of the participatory process (Peixoto and Fox 2016). In this case, this means looking at which petitions are actually successful in achieving their policy goals. Despite women's underrepresentation in petition creation, women actually have greater success than men on the platform. Petitions created by women are 1.36 times as likely to be successful as those created by men $(1.4 \%$ success versus $1.1 \%) .{ }^{13}$ Or, to put it another way, $51.8 \%$ of successful petitions are created by women, despite $55.9 \%$ of petitions being created by men, meaning women are more descriptively successful on the Change.org platform than men.

Figure 4 shows the results of a series of logistic regression models predicting petition success on the basis of gender and other controls. The effect of gender does not significantly change when we add country random intercepts and category fixed effects, showing that women's greater success is not due to them participating in more responsive countries or campaigning on issues to which decision makers are more responsive. However, the gender effect does become non-significant after we control for the number of signatures, suggesting that female petition creators' effectiveness is due to their greater mobilization ability and not due to women choosing easier issues to write petitions about. Given that the difference between men and women becomes insignificant after controlling for mobilization, we cannot reject the hypothesis that women's greater success is entirely due to their greater mobilization but it is possible that other factors may play a small role in the gender success gap. 
Figure 4: Logistic Regression Coefficients of Petition-Creator Gender on Probability of Petition Success with Different Sets of Controls

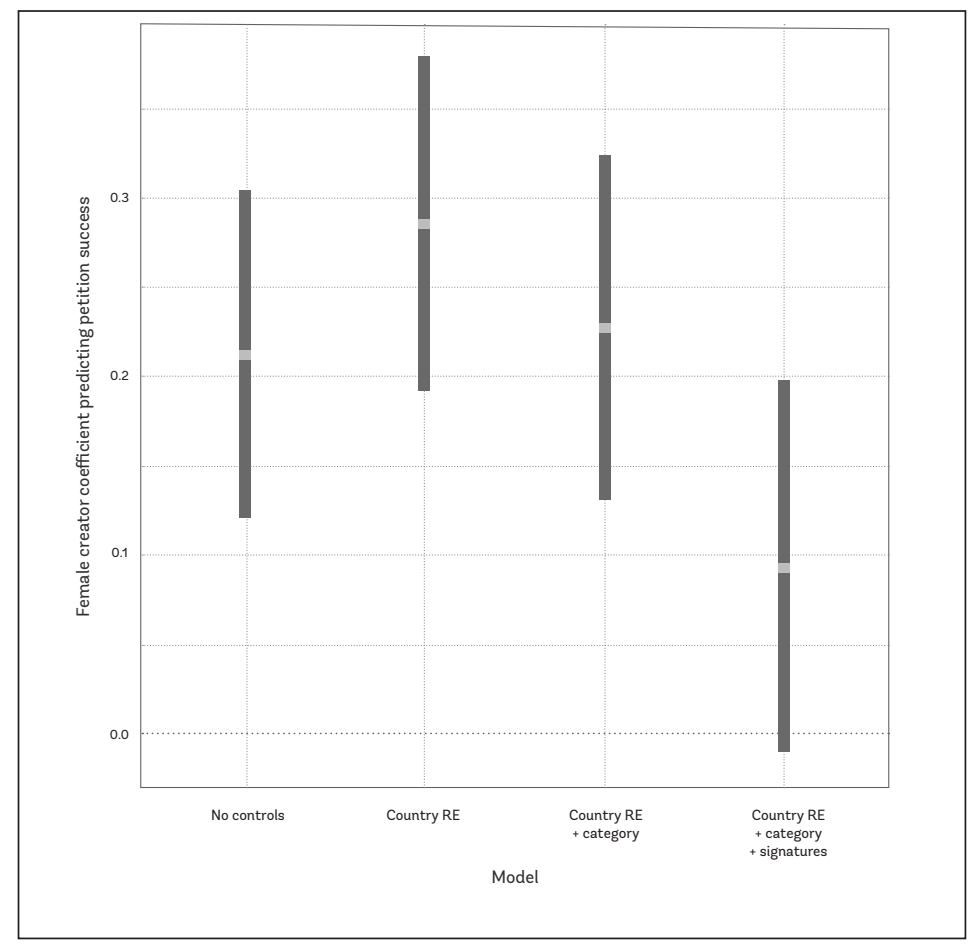

The over-performance of women in terms of descriptive success is a consistent pattern across different countries. Figure 5 shows the proportion of successful petitions created by women plotted against the proportion of all petitions created by women for the nine countries where there are sufficient numbers of successful petitions to reliably estimate the proportion. In all of these countries, women are responsible for a higher proportion of successful petitions than they are responsible for created petitions. In other words, women consistently have greater descriptive success than their thick participation alone would suggest. 
Figure 5: Proportion of Successful Online Petitions Created by Women Against the Proportion of All Petitions Created by Women for Countries with 50 or More Total Successful Petitions

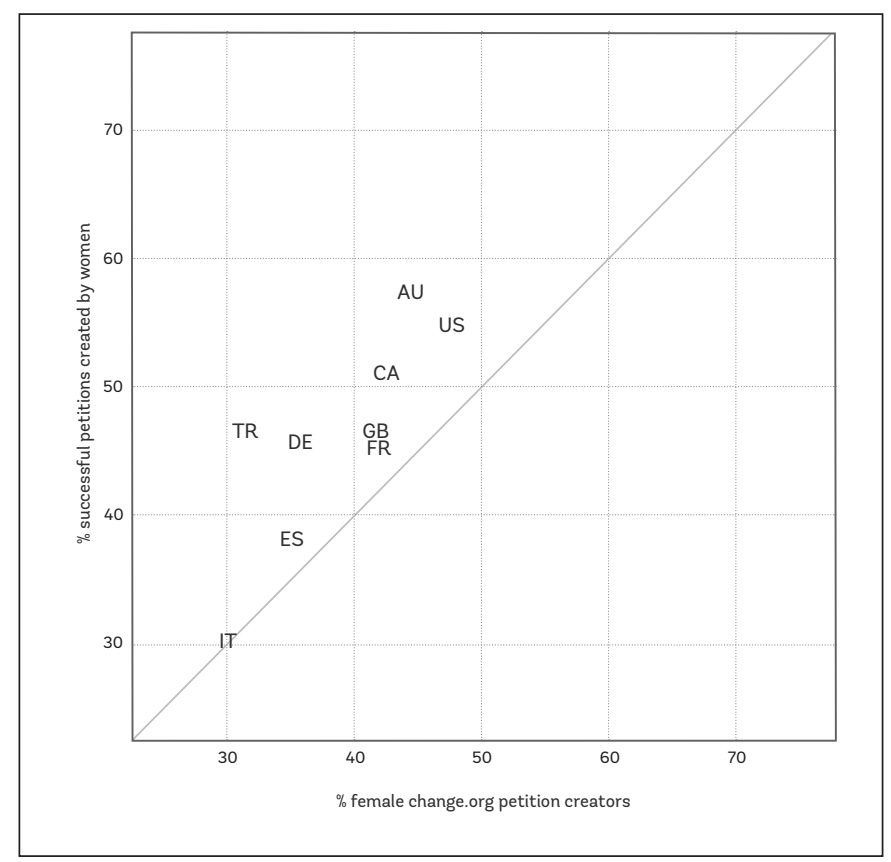

* Note: Gray line indicates identity line.

Why are female petition creators and female-preferred issues so successful on Change.org? The first reason is that female petition creators are substantially more effective at mobilizing signers. The mean number of signatures on a female-created petition is 432 compared with 273 for male-created petitions. ${ }^{14}$ This pattern also holds when looking at the 75 th percentile of signatures, with female petitions receiving 37 and male-created petitions receiving 14 signatures. 
Figure 6: The Relationship Between Signatures and Success

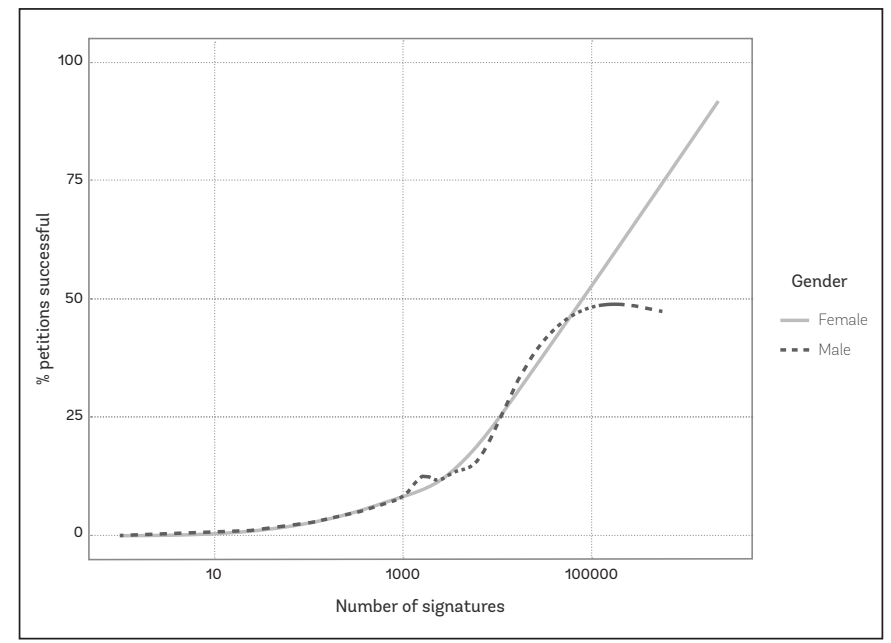

* Note: Loess regression line and 95\% confidence intervals shown.

Mobilization is an extremely strong predictor of success. Figure 6 shows the relationship between the number of signatures a petition receives and the probability that it will be successful. The lines between signatures and success are essentially identical for men and women for all except petitions with more than 100,000 signatures, which constitute a tiny fraction $(0.07 \%)$ of all petitions. ${ }^{15}$ While only a small percentage of all petitions are successful, the success rate is above $50 \%$ for the Change.org petitions receiving the most signatures. With the possible exception of the very largest petitions, the relationship between success and mobilization is almost identical for female and male petition creators.

A second reason for female petition creators' success is that female-created petitions attract more support from female Change.org users, who are overrepresented on the platform (as we showed in the participation section). Female petition creators are particularly successful at mobilizing signatures from female Change.org users: $60.7 \%$ of female signatures are on female-created petitions compared with $51.7 \%$ of male signatures on male-created petitions. However, this gap still means male users are disproportionately signing female-created petitions, although not to the same extent as women. This is consistent with research on voting behavior that finds women have higher tendency to vote for same-gender candidates than men (Hedlund et al. 1979; Zipp and Plutzer 1985; Smith and Fox 2001; Brians 2005). 
Is this homophily effect due to higher issue congruence between female creators and signers? Table 3 shows female petition creators have a higher issue congruence with female signers (86.1) than male signers (82.3), so there is certainly greater issue congruence between signers and creators of the same gender (male signers also have greater congruence with male creators than female signers do).

Table 2 uses linear probability models to show that this issue congruence between creators and signers of the same gender accounts for around 57\% of the observed gender homophily in signing. ${ }^{16}$

Table 2: Linear Probability Models Predicting a Signature Being on a Male- or Female-Created Petition

\begin{tabular}{|c|c|c|c|}
\hline & Model 1 & Model 2 & Model 3 \\
\hline Homophily & $0.105(0)$ & $0.073(0.001)$ & $0.031(0.002)$ \\
\hline R-squared & 0.044 & 0.046 & 0.115 \\
\hline Signatures & $4,061,816$ & $3,466,100$ & $3,466,100$ \\
\hline Users & $1,558,223$ & $1,259,927$ & $1,259,927$ \\
\hline Petitions & 80,030 & 38,012 & 38,012 \\
\hline Sample & $\begin{array}{l}\text { All signatures where creator and } \\
\text { signer gender are identifiable }\end{array}$ & $\begin{array}{l}\text { All signatures where creator and } \\
\text { signer gender are identifiable and } \\
\text { petition category is assigned }\end{array}$ & $\begin{array}{l}\text { All signatures where creator and } \\
\text { signer gender are identifiable and } \\
\text { petition category is assigned }\end{array}$ \\
\hline Fixed effects & Signer country & Signer country & $\begin{array}{l}\text { Signer country + petition category } \\
\text { (interacted with signer gender) }\end{array}$ \\
\hline
\end{tabular}

The remaining homophily in petition signing could be present for a number of reasons. While we do control for the content of petitions using the petition category, there are clearly other aspects of petition content not captured by this coarse measure. It is therefore possible female signers respond positively to other content of female-created petitions. The other possibility is that the difference reflects a basic preference for petitions created by people of the same gender among Change.org users. While petitions are not tagged explicitly as male- or female-created, the name and picture of the creator is displayed prominently on the petition page, so the information to make these decisions is readily available to users.

Before analyzing substantive success, we first need to establish whether men and women actually have different policy priorities on the Change.org platform. Table 3 examines this difference in terms of petition creation and 
petition signing. Women are disproportionately likely to create petitions in the categories of animals (10.5 percentage points more likely) and women's rights ( 3 percentage points more likely). Men are disproportionately likely to create petitions in the categories of economic justice (7.3 percentage points more likely) and human rights (4 percentage points more likely) (the differences between the preferences of female and male creators are statistically significant at the $1 \%$ level). We see similar patterns in women's choices of which petition categories to sign. Table 3 shows women are also more likely to sign petitions on the topics of animals and women's rights and men are disproportionately likely to sign petitions about human rights and economic justice.

These results show male and female users of the Change.org platform differ substantially in terms of the issues around which they choose to participate. This difference makes the question of substantive success on Change.org particularly important.

Table 3: Petition Categories of Male and Female Signers and Creators and Successful Petitions (in percent)

\begin{tabular}{|l|l|l|l|l|l|l|}
\hline Category & $\begin{array}{l}\text { Signatures } \\
\text { (all) }\end{array}$ & $\begin{array}{l}\text { Signatures } \\
\text { (female) }\end{array}$ & $\begin{array}{l}\text { Signatures } \\
\text { (male) }\end{array}$ & $\begin{array}{l}\text { Creator } \\
\text { (female) }\end{array}$ & $\begin{array}{l}\text { Creator } \\
\text { (male) }\end{array}$ & Successful \\
\hline Animals & 15.5 & 19.1 & 9.5 & 16.8 & 6.3 & 15.4 \\
\hline Criminal Justice & 14.6 & 15.0 & 14.0 & 10.6 & 10.0 & 7.9 \\
\hline Economic Justice & 13.5 & 11.7 & 16.5 & 11.1 & 18.4 & 9.7 \\
\hline Education & 6.5 & 6.4 & 6.7 & 11.1 & 11.4 & 15.3 \\
\hline Environment & 5.1 & 4.8 & 5.7 & 7.5 & 10.0 & 8.1 \\
\hline Gay Rights & 8.4 & 8.1 & 9.0 & 3.6 & 6.2 & 6.6 \\
\hline Global Poverty & 0.0 & 0.0 & 0.0 & 0.2 & 0.2 & 0.0 \\
\hline Health & 7.7 & 8.0 & 7.3 & 8.3 & 6.8 & 8.5 \\
\hline Human Rights & 16.8 & 14.6 & 20.3 & 17.6 & 21.6 & 15.9 \\
\hline Immigrant Rights & 1.6 & 1.5 & 1.7 & 1.8 & 1.6 & 3.9 \\
\hline Other & 0.1 & 0.1 & 0.1 & 2.0 & 1.9 & 0.0 \\
\hline Sustainable Food & 2.5 & 2.5 & 2.5 & 2.4 & 1.8 & 1.6 \\
\hline Human Trafficking & 1.2 & 1.3 & 1.0 & 2.1 & 1.7 & 2.4 \\
\hline Women's Rights & 6.5 & 7.0 & 5.6 & 5.0 & 2.0 & 4.8 \\
\hline N & $3,466,100$ & $2,151,043$ & $1,315,057$ & 31,100 & 30,842 & 2,161 \\
\hline
\end{tabular}

We also consider the issue agenda addressed by decision makers by looking at the issues represented among successful petitions. The previous sections showed women and men clearly create and sign petitions on substantially 
different topics. We use congruence scores to measure the similarity of two sets of agendas, allowing us to compare the implemented agenda (the issues in successful petitions) to the agenda of female and male petition creators.

Table 4: Congruence Scores for the Agendas of Different Groups of Petition Signers and Creators and Successful Petitions

\begin{tabular}{|l|l|l|}
\hline Agenda 1 & Agenda 2 & Congruence \\
\hline Signatures (all) & Signatures (female) & 95.15 \\
\hline Signatures (all) & Signatures (male) & 91.95 \\
\hline Signatures (all) & Creator (female) & 87.15 \\
\hline Signatures (all) & Creator (male) & 77.95 \\
\hline Signatures (all) & Successful & 83.95 \\
\hline Signatures (female) & Signatures (male) & 87.10 \\
\hline Signatures (female) & Creator (female) & 86.10 \\
\hline Signatures (female) & Creator (male) & 73.50 \\
\hline Signatures (female) & Successful & 82.50 \\
\hline Signatures (male) & Creator (female) & 82.30 \\
\hline Signatures (male) & Creator (male) & 85.10 \\
\hline Signatures (male) & Successful & 78.40 \\
\hline Creator (female) & Creator (male) & 83.20 \\
\hline Creator (female) & Successful & 89.60 \\
\hline Creator (male) & Successful & 79.20 \\
\hline $\begin{array}{l}\text { Note: } \text { Higher congruence indicates the issues in two sets of petitions are more similar to each other. } \\
\text { All differences are significant at the 1\% level using the chi-squared test. }\end{array}$ & \\
\hline
\end{tabular}

Comparing these agendas shows the female agenda is much closer to the outputs of Change.org than the male agenda. As with raw petition success, female petition creators are successful in terms of congruence between the issues in their demands and the issues addressed by decision makers. As we can see in Table 4, successful petitions have a more similar distribution of issues to female petition creators (congruence score of 89.6) than the issues of male petition creators (congruence score of 79.2). The same difference is observed for the agendas of female and male petition signers (the female agenda has higher congruence with policy outputs than the male signer agenda does).

We can also compare substantive success cross-nationally. Using the same nine countries with sufficient successes, we estimate congruence scores for male and female creators compared with the policy agenda of the successful 
petitions. This allows us to compare whether the policy agenda is closer to male or female preferences in each country. Figure 7 shows the congruence scores for male and female petition creators (against policy outputs). In seven out of nine countries, women have higher congruence with policy outputs than men and, in the other two cases, the level of substantive success for men and women is essentially identical. Overall, we see a consistent pattern that women are equally or more substantively successful than men on the Change. org platform.

Figure 7: Substantive Success for Men and Women Across Nine Countries with More than 50 Successful Petitions in the Dataset

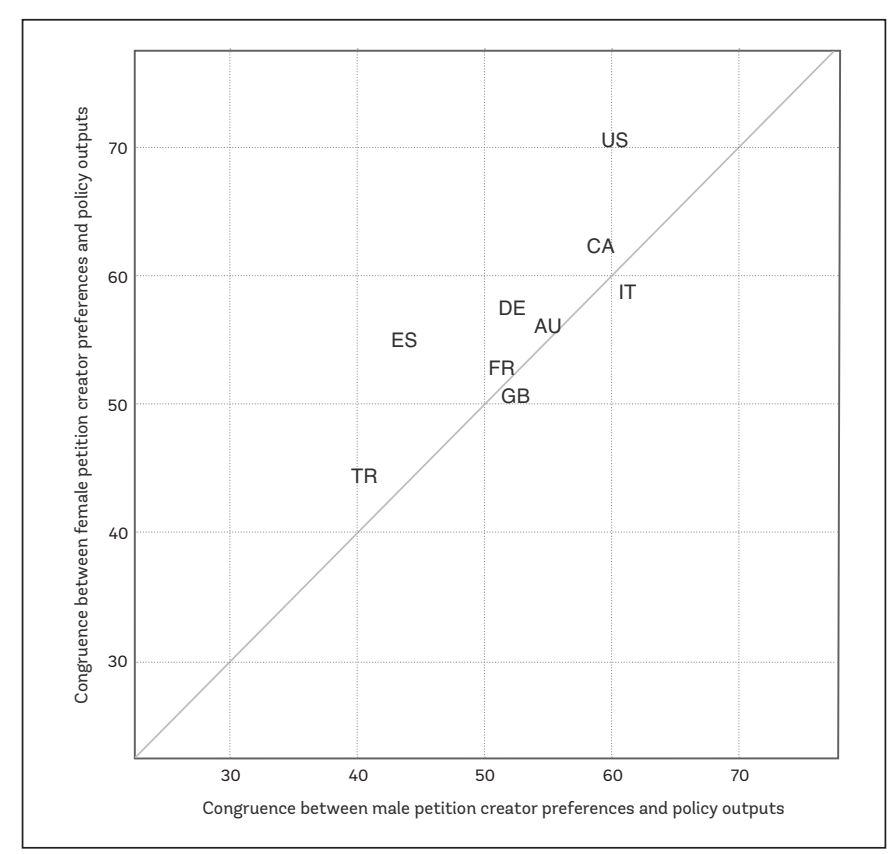

\section{Petitioning and Electoral Politics}

How do gender participation and success differ between petitioning and electoral politics? Figure 8 shows the conceptual links between the different forms of participation and success we discussed in the theory section, but with the results of this study filled in, and the same exercise for the electoral politics literature. 
Figure 8: Conceptual Chart of Results (Petitioning) Compared to Findings from the Electoral Politics Literature

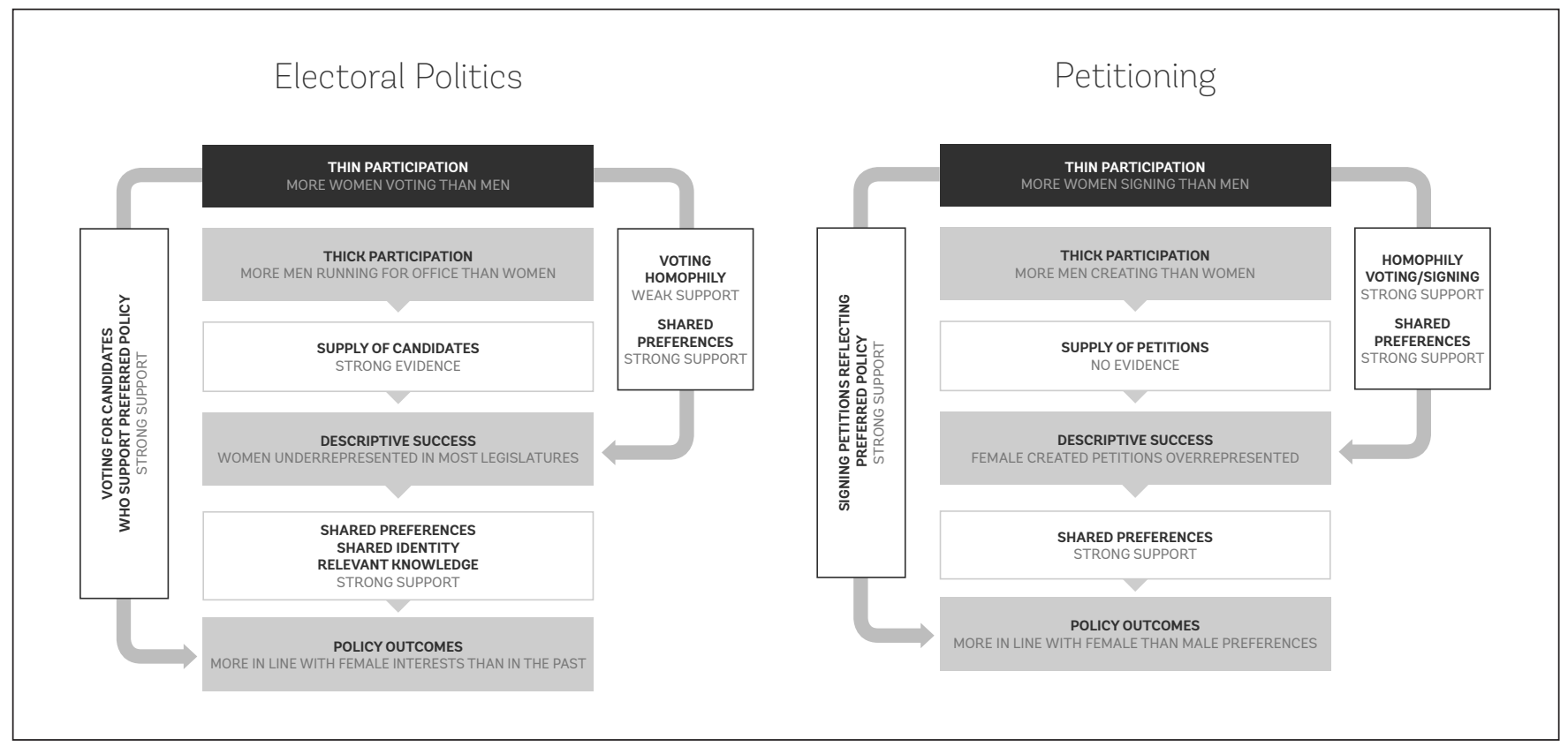

The two domains have remarkably similar patterns of female participation. In both petitioning and electoral politics, there is a split in gender participation between thin and thick actions. Women are well represented and often overrepresented in signing petitions. Recent literature on Western democracies largely shows a similar picture for female turnout. Similarly, women are less likely to create petitions and run for office (thick participation).

However, the two domains diverge substantially when we move to the question of success. In electoral politics, the limited choice sets of voting strongly link thick participation (running for office) and descriptive success. Therefore women's lower participation in running for office translates directly to lower descriptive success in legislatures.

We do not find evidence linking thick participation and descriptive success in the case of petitioning. The difference between these modes is probably due to the sharp cutoff for female descriptive success in the electoral context. If no woman runs for office there is zero probability that a woman will be elected. In the case of petitions, there are so many fewer successful petitions compared to attempts that there are no hard cutoffs. Every user can potentially sign a female-created petition. 
Similarly the disaggregated nature of petitions means users can sign petitions based on exactly the issues they think are important rather than choosing bundles of policies instantiated in a candidate or party. Signing on the basis of issue preference increases descriptive success because 1) female users have more similar agendas to female creators than to male creators and 2) female users are overrepresented on Change.org. To summarize, in electoral politics, the thick participation of women is the primary determinant of descriptive success, whereas in petitioning the thin participation of women is the primary determinant.

We demonstrate this effect using a simulation where the probability that an individual $i$ signs a petition $j$ is proportional to $X=\mu+\alpha_{j} \cdot \beta_{1} I\left(g_{i}=g_{j}\right) \cdot \beta_{2}\left(c_{i}=c_{j}\right)$, where $g_{x}$ is the gender of $x$ (either petition creator or signer) and $c_{x}$ is the category $x$ cares most about or the petition is about. The probability that $i$ signs $j$ is then:

$$
\frac{\exp \left(x_{i j}\right)}{\sum_{\mathrm{k}=1}^{\mathrm{n}} \exp \left(\mathrm{x}_{\mathrm{ik}}\right)}
$$

We then simulate the behavior of $200,000,000$ signers and 100,000 petitions, where $\beta_{1}=1.5 \beta_{2}=3, a_{j}$, is drawn from a normal distribution with mean 0 and standard deviation of 1 , and $\mu$ is set so that $X>=0$. We set the level of female thick participation at 33\% and the level of thin participation at $60 \%$ and simulate the number of signatures each petition would be expected to receive. As a simplification, we assume that the most popular petitions succeed and that as the level of overall success increases, the next most popular petitions are added to the winning set. Figure 9 shows the level of female descriptive success depending on the proportion of petitions that are successful overall. With very low rates of overall success, female descriptive success approaches the level of female thin participation, whereas with the highest rates of success, the level of female descriptive success approaches the level of female thick participation.

Since just $1.2 \%$ of all petitions in our sample are successful, Change.org occupies the far left side of this chart. Electoral politics is complicated by different electoral systems, and the percentage of viable candidates who succeed in most majoritarian systems is somewhere between half and a third in a given district (it is relatively rare that there are four-way races where all candidates are perceived as viable). Electoral politics would therefore sit somewhere around the middle of the chart, where the level of thick participation is the dominant factor in determining descriptive success. 
Figure 9: Simulated Descriptive Success for Women Depending on the Proportion of Thick Participation that Results in Success

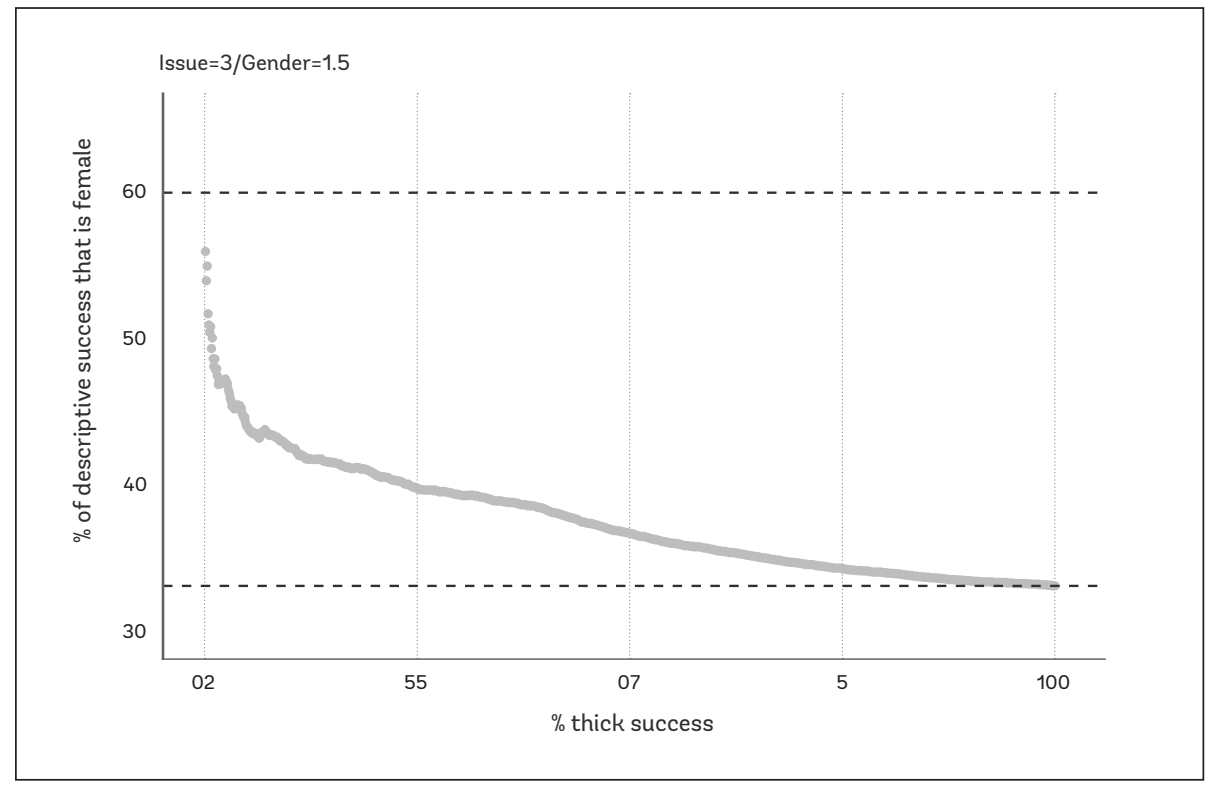

Note: The upper dotted line indicates the percentage of women thin participators in the simulation and the lower line indicates the percentage of women thick participators in the simulation.

As with electoral politics, there is a link between descriptive success and substantive success in petitioning. Female petition creators have an agenda more closely aligned to female users' preferences than male users' preferences; female creators' higher rate of successful petitions means that the implemented policy agenda that comes out of Change.org is closer to female preferences. This link is primarily driven by the strong relationship between mobilization and success. This connection is also generally present in electoral politics. ${ }^{17}$ However, in the electoral domain, this link is mediated by party and candidate platforms, unlike in direct democracy and petitioning.

\section{Conclusions}

Overall, our results show online petition signing reproduces the pattern of thin/thick participation seen in representative democracy. Women participate at high rates in the thin form of participation of signing petitions but under-participate in the thicker form of participation that is petition creation. However, our results do not suggest that underrepresentation in thick participation translates into poor descriptive or substantive success for women. 
Looking at the issues women choose to sign and create petitions about, the agenda that is actually implemented is much closer to the issues women choose to focus on than those on which men focus.

Our findings suggest that women's descriptive and substantive success is primarily attributable to their greater mobilization of petition signers and our evidence is consistent with this being the entire explanation for the gender gap. However, the reasons for women's greater mobilization ability should be further explored in future research. Our analysis attributes some of it to female creators' choice of issues and some to female signers' preference for female creators. However, this does not explain the entire gender mobilization gap as even male signers prefer female-created petitions.

How much should we expect these results to generalize? Change.org is certainly not representative of all forms of non-electoral participation or even e-petitioning. The platform appears to implicitly encourage progressive causes (the choice of featured petitions and the category choices are examples of this) and narrow goals. On the other hand, the lower rate of female thick participation is strikingly consistent across the different countries studied and is also reflected in previous studies of offline participation. Similarly, the over-performance of female petition creators on the platform seems to result from structural features of the platform (high ratios of thick participation to descriptive success) rather than the ideological balance of the platform. We therefore expect that we would find similar results anywhere the following conditions hold: 1) women are underrepresented in thick participation compared with their thin participation; 2) women and men have differing policy preferences; and 3) the ratio of thick participation to descriptive success is high.

The mechanism outlined in this paper also has implications for other domains. Systems that allow voters to choose between many possible viable candidates (including ones from the same party) should, ceteris paribus, tend to increase female descriptive success compared with majoritarian systems. The California "jungle primary" system where all candidates compete in a first-round, nonpartisan primary and the top two contenders (regardless of party label) compete in the runoff might be such a system, although this would depend on female turnout in the primaries, the level of gender-based voting, and the extent to which the primaries are actually competitive. 
There are numerous policy implications and areas of future research. First, our findings suggest the opportunity for online platforms, and e-petitions in particular, to create new pathways for female substantive success. By leveraging the potential of thin participation, Change.org illustrates one potential pathway for greater substantive female policy success. There may be other substantive participation opportunities to empower female networks and other aspects traditionally associated with descriptive success through more effective (online and offline) mobilization. These findings should also temper rushed criticisms against thin forms of participation, often dismissed as "push-button democracy," "clicktivism," and "slacktivism" (Drumbl 2012; Tsaliki 2002; Coleman, Taylor, and van de Donk 1999; Morozov 2011; Karpf 2010). Rather these results lend support to a more positive stance on the democratic and inclusive aspects of thinner and "viral" types of engagement (Karpf 2010; Fung, Russon Gilman, and Shkabatur 2013). Second, our research suggests there may be untapped policy opportunities for women's preferences to enter the policy arena on topics they view as particularly salient. Understanding the potency of women's issues could provide numerous opportunities for engaging women in the policymaking process. Finally, our findings demonstrate the ability for platform design to offer more meaningful substantive participation opportunities than the current electoral structure in established democracies. This finding has potential policy implications for other digital forms of engagement across a wide range of applications and cases.

Further research is needed to see precisely if and how empowering women on digital platforms can translate into greater descriptive success in other contexts. Second, additional research could assess the perceived salience of Change.org petitions as well as how thick participation on the platform translates into enhanced feelings of political efficacy or engagement with other spheres of civic and political life. Finally, additional research is needed on the role of policymakers and traditional party structures in female descriptive and substantive success. The unmediated, direct democracy aspects of Change.org lead to more substantive female success, therefore additional research into the channels and gatekeepers of substantive female success would be valuable. 


\section{Notes}

1. Change.org reports 177 million users; Avaaz reports 43 million users; 38 Degrees reports 2.5 million users. The largest petition on the government-run petition. parliament.uk received 4.1 million signatures. We the People, the US White House petitioning website, reports 19.5 million total users (of which 12.3 million are verified). Additionally, many interest groups and political movements host petitions as part of their campaign actions. All of these figures are based on the most recent available information listed on the relevant websites.

2. As of 16th November 2016, Change.org reports on its main page that 177,301,113 people have taken action through its platform. This figure is consistent with our analysis of the Change.org API data in this paper.

3. This is not to say that creating a petition is as costly an activity as running for office, merely that it 1 ) is more costly than signing a petition and 2) defines the choice set for petition signers.

4. Three examples include: businessnewsdaily.com/3637-business-changes-year .html, npr.org/2012/03/16/148556371/petitions-are-going-viral-sometimes-to -great-success, and huffingtonpost.co.uk/2015/06/22/changeorg-successful -petitions_n_7635750.html.

5. For an in-depth discussion of the various concepts of representation, see Urbinati and Warren 2008

6. A private certification that identifies for-profit companies that achieve a minimum "social and environment" performance score.

7. See http://epaperbeta.timesofindia.com/Article.aspx?eid=31806\&articlexml =Bluru-moms-lead-the-charge-of-activist-brigade-07032016004019 and https:// www.change.org/p/karnataka-education-minister-kimmane-ratnakar-issue -directive-to-all-schools-in-bangalore-to-impose-security-measures-for-the -safety-of-children.

8. In computer programming, application-programming interface (API) refers to routines, protocols, and tools for third parties to build software and access data.

9. At the other end of the spectrum, 15 users are from Svalbard and Jan Mayen (Norwegian islands in the Arctic Ocean) and 17 are from the island of Niue (a South Pacific Ocean island country). Because these samples are so small, we excluded 40 countries with 75 or fewer users from the analysis. The largest of these was Mauritania with 75 users.

10. Reported in the Centers for Disease Control and Prevention Table 20 Publication.

11. In terms of measurement, Change.org provides a status measure for every petition retrieved through their API. This status can take the values of preview, open, closed, and victory. Preview petitions are discarded as they are not live on the website. We also discard open petitions, as these have not been determined to be successful or not. This leaves closed petitions, which we consider to have been unsuccessful and victory petitions, which we consider to be 
successful. Petitions automatically close one year after their last edit, so that petitions that are no longer actively being managed close in a reasonable space of time. It is possible for petition makers to reopen their petition, so we see the closed status as reasonably approximating whether a petition goal is being actively pursued through that petition.

12. In order to limit research assistant time, we set a maximum limit of five minutes for a researcher to examine each petition.

13. This difference is significant using Pearson's Chi-squared test with simulated $\mathrm{p}$-value $\left(\mathrm{X}^{2}=76.92, \mathrm{p}<0.001\right)$.

14. This difference is significant using the Welch two sample t-test on either the unadjusted number of signatures $(\mathrm{t}=5.24, \mathrm{p}<0.001)$ or the natural $\log$ of the signature count $+1(\mathrm{t}=47.29, \mathrm{p}<0.001)$.

15. There are 57 female and 40 male victories on petitions with more than 100,000 signatures, compared with 39 female and 37 male failures. The differences at these high levels therefore cannot be driving the overall differences between male and female success.

16. This is calculated by $(7.3-3.1) / 7.3=0.575$ using the homophily coefficients in Table 2.

17. Notable exceptions occur in majoritarian systems where the number of votes a party gets does not always directly translate into access to power, such as with the US Electoral College system. 


\section{References}

Albrecht, Steffen. 2006. "Whose Voice Is Heard in Online Deliberation?: A Study of Participation and Representation in Political Debates on the Internet." Information, Communication \& Society 9 (1): 62-82. doi:10.1080/13691180500519548.

Anduiza, Eva, Aina Gallego, and Marta Cantijoch. 2010. "Online Political Participation in Spain: The Impact of Traditional and Internet Resources." Journal of Information Technology \& Politics 7 (4): 356-68. doi:10.1080/19331681003791891.

Ausserhofer, Julian, and Axel Maireder. 2013. "NATIONAL POLITICS ON TWITTER: Structures and Topics of a Networked Public Sphere.” Information, Communication \& Society 16 (3): 291-314. doi:10.1080/1369118X.2012.756050.

Best, Samuel J., and Brian S. Krueger. 2005. "Analyzing the Representativeness of Internet Political Participation.” Political Behavior 27 (2): 183-216. doi:10.1007 /s11109-005-3242-y.

Bettes, William Mark. 2015. "Rise of the Mama Grizzlies: Rethinking Women's Descriptive and Substantive Representation in the American States." University of Kansas. https://kuscholarworks.ku.edu/handle/1808/19014.

Beutel, Ann M., and Margaret Mooney Marini. 1995. "Gender and Values." American Sociological Review 60 (3): 436-48. doi:10.2307/2096423.

Blais, André, Elisabeth Gidengil, and Neil Nevitte. 2004. "Where Does Turnout Decline Come From?” European Journal of Political Research 43 (2): 221-36. doi:10.1111/j.1475-6765.2004.00152.x.

Brians, Craig Leonard. 2005. "Women for Women?: Gender and Party Bias in Voting for Female Candidates." American Politics Research 33 (3): 357-75. doi:10.1177/1532673X04269415.

Burns, Nancy, Kay Lehman Schlozman, and Sidney Verba. 2001. The Private Roots of Public Action. Cambridge, MA: Harvard University Press.

Burrell, Barbara C. 1993. "Party Decline, Party Transformation, and Gender Politics: The USA.” In Gender and Party Politcs, edited by Joni Lovenduski and Pippa Norris. London: Sage Publications.

Celis, Karen, Sarah Childs, Johanna Kantola, and Mona Lena Krook. 2008. "Rethinking Women's Substantive Representation.” Representation 44 (2): 99-110.

Chattopadhyay, Raghabendra, and Esther Duflo. 2004. "Women as Policy Makers: Evidence from a Randomized Policy Experiment in India." Econometrica 72 (5): 1409-43.

Chhibber, Pradeep. 2002. "Why Are Some Women Politically Active? The Household, Public Space, and Political Participation in India." International Journal of Comparative Sociology 43 (305): 409-29.

Childs, Sarah. 2004. "A British Gender Gap? Gender and Political Participation." The Political Quarterly 75 (4): 422-24. doi:10.1111/j.1467-923X.2004.00646.x.

Childs, Sarah, and Mona Lena Krook. 2009. “Analysing Women's Substantive Representation: From Critical Mass to Critical Actors." Government and Opposition 44 (2): 125-145.

Coleman, Stephen, John Taylor, and Wim van de Donk. 1999. Parliament in the Age of the Internet. Oxford University Press Oxford. https://pdfs.semanticscholar.org/ 4077/978776592cd433122f59fe15307de8917e0b.pdf. 
Conway, M. Margaret. 2001. "Women and Political Participation.” PS: Political Science \& Politics 34 (2): 231-33.

Corrin, Chris, ed. 1992. Superwomen and the Double Burden: Women's Experiences of Change in East Central Europe and the Former Soviet Union. London: Scarlet.

Costantini, Edmond. 1990. "Political Women and Political Ambition: Closing the Gender Gap." American Journal of Political Science 34 (3): 741-70. doi: $10.2307 / 2111397$.

Dalton, Russell, Alix Van Sickle, and Steven Weldon. 2009. "The Individual-institutional Nexus of Protest Behaviour." British Journal of Political Science 40 (1): 51.

di Gennaro, Corinna, and William Dutton. 2006. "The Internet and the Public: Online and Offline Political Participation in the United Kingdom." Parliamentary Affairs 59 (2): 299-313.

Dodson, Debra L. 2006. The Impact of Women in Congress. Oxford University Press on Demand. https://books.google.com/books?hl=en\&lr=\&id

$=$ rCgSDAAAQBAJ\&oi $=$ fnd\&pg $=$ PR5\&dq $=$ Dodson,+ Debra + L. +2006

.+The+Impact + of + Women+in+Congress. + New + York:+Oxford+ University\&ots $=\mathrm{kZBiFJdsxj \& sig=OLeafIi8-HJcKh2ltOT7SlkKkzk.}$

Drumbl, Mark A. 2012. "Child Soldiers and Clicktivism: Justice, Myths, and Prevention." Journal of Human Rights Practice 4 (3): 481-485.

Engeli, Isabelle, Thanh-Huyen Ballmer-Cao, and Marco Giugni. 2006. "Gender Gap and Turnout in the 2003 Federal Elections." Swiss Political Science Review 12 (4): 217-42. doi:10.1002/j.1662-6370.2006.tb00066.x.

Evans, Eds Geoffrey, Pippa Norris, and A. Gender-Generation Gap. 2017. "A CRITICAL ELECTION? UNDERSTANDING THE 1997 BRITISH ELECTION IN LONG-TERM PERSPECTIVE.” Accessed January 11. https://aceproject.org/ ero-en/topics/electoral-participation/turnout/a-gender-generation-gap.pdf.

Fisher, Bonnie S., Craig T. Cobane, Thomas M. Vander Ven, and Francis T. Cullen. 1998. "How Many Authors Does It Take to Publish an Article? Trends and Patterns in Political Science." PS: Political Science \& Politics 31 (4): 847-56. doi: $10.2307 / 420730$.

Fox, Richard L., and Jennifer L. Lawless. 2014. "Uncovering the Origins of the Gender Gap in Political Ambition." American Political Science Review 108 (3): 499-519.

Franceschet, Susan, and Jennifer M. Piscopo. 2008. "Gender Quotas and Women's Substantive Representation: Lessons from Argentina." Politics \& Gender 4 (03): 393-425.

Fung, Archon, Hollie Russon Gilman, and Jennifer Shkabatur. 2013. "Six Models for the Internet + Politics." International Studies Review 15 (1): 30-47.

Hagemann, Carlo. 2002. "Participation in and Contents of Two Dutch Political Party Discussion Lists on the Internet." Javnost/The Public 9 (2): 61-76.

Hedlund, Ronald D., Patricia K. Freeman, Keith E. Hamm, and Robert M. Stein. 1979. "The Electability of Women Candidates: The Effects of Sex Role Stereotypes." The Journal of Politics 41 (2): 513-24. doi:10.2307/2129776.

Inglehart, Ronald, and Pippa Norris. 2000. "The Developmental Theory of the Gender Gap: Women's and Men's Voting Behavior in Global Perspective." International Political Science Review 21 (4): 441-63. doi:10.1177/0192512100214007. 
Jankowski, Nicholas, and Martine van Selm. 2000. "The Promise and Practice of Public Debate in Cyberspace." In Digital Democracy: Issues of Theory and Practice. Thousand Oaks, CA: Sage.

Jensen, Jakob Linaa. 2003. "Virtual Democratic Dialogue? Bringing Together Citizens and Politicians." Information Polity 8 (1): 29-47.

Johnson, Thomas J., and Barbara K. Kaye. 2003. "A Boost or Bust for Democracy? How the Web Influenced Political Attitudes and Behaviors in the 1996 and 2000 Presidential Elections." Harvard International Journal of Press and Politics 8 (3): 9-34.

Karpf, David. 2010. "Online Political Mobilization from the Advocacy Group's Perspective: Looking beyond Clicktivism." Policy \& Internet 2 (4): 7-41.

Karpowitz, Christopher F., Tali Mendelberg, and Lee Shaker. 2012. "Gender Inequality in Deliberative Participation." American Political Science Review 106 (3): 533-47.

Lawless, Jennifer L., and Richard L. Fox. 2005. It Takes a Candidate: Why Women Don't Run for Office. New York: Cambridge University Press.

- 2010. It Still Takes a Candidate: Why Women Don't Run for Office. New York: Cambridge University Press.

Leighley, Jan E., and Jonathan Nagler. 2013. Who Votes Now?: Demographics, Issues, Inequality, and Turnout in the United States. Princeton University Press.

Leigninger, Matt. 2014. "What We're Talking About When We Talk About the 'Civic Field' (And Why We Should Clarify What We Mean)." Journal of Public Deliberation 10 (1): 1-6.

Lien, Pei-Te. 1998. "Does the Gender Gap in Political Attitudes and Behavior Vary Across Racial Groups?" Political Research Quarterly 51 (4): 869-94. doi:10.1177/106591299805100402.

Lindner, Ralf, and Ulrich Riehm. 2011. "Broadening Participation Through E-Petitions? An Empirical Study of Petitions to the German Parliament." Policy \& Internet 3 (1): 1-23.

Mansbridge, Jane. 1999. "Should Blacks Represent Blacks and Women Represent Women? A Contingent 'yes."” The Journal of Politics 61 (03): 628-657.

Marien, Sofie, Marc Hooghe, and Ellen Quintelier. 2010. "Inequalities in NonInstitutionalised Forms of Political Participation: A Multi-Level Analysis of 25 Countries." Political Studies 58 (1): 187-213.

Marom, Dan, Alicia Robb, and Orly Sade. 2016. "Gender Dynamics in Crowdfunding (Kickstarter): Evidence on Entrepreneurs, Investors, Deals and Taste-Based Discrimination." SSRN Scholarly Paper ID 2442954. Rochester, NY: Social Science Research Network. https://papers.ssrn.com/abstract=2442954.

Mislove, Alan, Sune Lehmann, Yong-Yeol Ahn, Jukka-Pekka Onnela, and J. Niels Rosenquist. 2011. "Understanding the Demographics of Twitter Users." ICWSM 11: 5 th.

Morozov, Evgeny. 2011. "The Dark Side of Internet Freedom: The Net Delusion." New York: Public Affairs.

Nabatchi, Tina, and Matt Leighninger. 2015. Public Participation for 21st Century Democracy. John Wiley \& Sons. https://books.google.com/books?hl $=$ en $\& 1 \mathrm{r}=\& \mathrm{id}=\mathrm{K} 4 \mathrm{XgCAAAQBAJ} \& \mathrm{oi}=\mathrm{fnd} \& \mathrm{pg}=\mathrm{PA} 241 \& \mathrm{dq}=\mathrm{Nabatchi}+$ and +Leighninger+2015\&ots=HuDD2Lb0Ot\&sig=LJqb0QkVOIshu418rGn27Lc-yuo. 
Niven, David. 1998. The Missing Majority. The Recruitment of Women as State Legislative Candidates. Westport, CT: Praeger.

Norris, Pippa. 2001. Digital Divide: Civic Engagement, Information Poverty, and the Internet Worldwide. Cambridge University Press. https://books.google.com /books?hl=en\&lr=\&id=wfNPdyiwbYQC\&oi=fnd\&pg=PP11\&dq=pippa +norris+2001\&ots=gzjK2frZjK\&sig=wqHUGzmMQ262fW0PfLnzUDBpeCE.

Norris, Pippa, and Joni Lovenduski. 1995. Political Recrtuiment. Cambridge: Cambridge University Press.

Paxton, Pamela. 1997. "Women in National Legislatures: A Cross-National Analysis." Social Science Research 26 (4): 442-464.

Pearson, Kathryn, and Logan Dancey. 2011. "Speaking for the Underrepresented in the House of Representatives: Voicing Women's Interests in a Partisan Era." Politics \& Gender 7 (4): 493-519.

Peixoto, T., \& Fox, J. (2016). When does ICT-enabled citizen voice lead to government responsiveness? IDS Bulletin, 47(1).

Phillips, Anne. 1998. Feminism and Politics. Oxford University Press on Demand. https://books.google.com/books?hl=en\&lr=\&id=2vj1SnVwT1YC\&oi=fnd\&pg $=\mathrm{PP} 2 \& \mathrm{dq}=\% 22 \mathrm{Feminism}+$ and + Politics\%22\&ots=6kJ5_Vz9O1\&sig $=$ WBMM3DIAHydOj5vNnyQKblKbVec.

Pitkin, Hanna Fenichel. 1967. The Concept of Representation. University of California Press. https://books.google.com/books?hl=en\&lr=\&id=AgUVWLswTNEC\&oi $=$ fnd\&pg $=$ PA1\&dq $=$ Pitkin, + Hanna + F. $+1967 .+$ The + Concept + of + Representation .+Berkeley:+University + of + California + Press.\&ots $=15 \mathrm{wPeNYmu} 8 \&$ sig $=$ KIykrO4rlI8vgzAPetKIFv51BxQ.

Rahat, Gideon, and Reuven Y. Hazan. 2001. "Candidate Selection Methods: An Analytical Framework.” Party Politics 7 (3): 297-322.

Schlozman, Kay Lehman, Sidney Verba, and Henry E. Brady. 2010. "Weapon of the Strong? Participatory Inequality and the Internet." Perspectives on Politics 8 (02): 487-509.

Schwindt-Bayer, Leslie A. 2006. "Still Supermadres? Gender and the Policy Priorities of Latin American Legislators." American Journal of Political Science 50 (3): $570-585$.

Shapiro, Robert Y., and Harpreet Mahajan. 1986. "Gender Differences in Policy Preferences: A Summary of Trends from the 1960s to the 1980s." Public Opinion Quarterly 50 (1): 42-61. doi:10.1086/268958.

Sheppard, Jill. 2015. "Online Petitions in Australia: Information, Opportunity and Gender." Australian Journal of Political Science 50 (3): 480-495.

Sjoberg, Fredrik M., Jonathan Mellon, and Tiago Peixoto. 2016. "The Effect of Government Responsiveness On Future Political Participation.” Public Administration Review.

Sloan, Luke, Jeffrey Morgan, William Housley, Matthew Williams, Adam Edwards, Pete Burnap, and Omer Rana. 2013. "Knowing the Tweeters: Deriving Sociologically Relevant Demographics from Twitter.” Sociological Research Online 18 (3): 7.

Smith, Eric R. A. N., and Richard L. Fox. 2001. "The Electoral Fortunes of Women Candidates for Congress.” Political Research Quarterly 54 (1): 205-21. doi:10.1177/106591290105400111. 
Spada, Paolo, Jonathan Mellon, Tiago Peixoto, and Fredrik M. Sjoberg. 2016. "Effects of the Internet on Participation: Study of a Public Policy Referendum in Brazil." Journal of Information Technology \& Politics, February. http://papers.ssrn.com /abstract $=2571083$.

Stromer-Galley, Jennifer. 2002. "New Voices in the Public Sphere: A Comparative Analysis of Interpersonal and Online Political Talk." Javnost/The Public 9 (2): 23-42.

Stromer-Galley, Jennifer. 2002. "New Voices in the Public Sphere: Political Conversation in the Age of the Internet." Doctoral dissertation. Philadelphia: Annenberg School for Communication, University of Pennsylvania.

Swers, Michele L. 2002. The Difference Women Make: The Policy Impact of Women in Congress. Chicago, IL: University of Chicago Press.

- 2013. Women in the Club: Gender and Policy Making in the Senate. Chicago, IL: University of Chicago Press.

Tsaliki, Liza. 2002. "Online Forums and the Enlargement of Public Space: Research Findings from a European Project." Javnost-The Public 9 (2): 95-112.

Urbinati, Nadia, and Mark E. Warren. 2008. "The Concept of Representation in Contemporary Democratic Theory.” Annu. Rev. Polit. Sci. 11: 387-412.

Verba, Sidney, Kay Lehman Schlozman, and Henry E. Brady. 1995. Voice and Equality: Civic Voluntarism in American Politics. Cambridge, MA: Harvard University Press.

Vicente, María Rosalía, and Amparo Novo. 2014. “An Empirical Analysis of E-Participation. The Role of Social Networks and E-Government over Citizens' Online Engagement." Government Information Quarterly 31 (3): 379-387.

Wängnerud, Lena. 2009. "Women in Parliaments: Descriptive and Substantive Representation." Annual Review of Political Science 12 (1): 51-69.

Whitehead, John T., and Michael B. Blankenship. 2000. "The Gender Gap in Capital Punishment Attitudes: An Analysis of Support and Opposition." American Journal of Criminal Justice 25 (1): 1. doi:10.1007/BF02886807.

Wilhelm, Anthony G. 2000. Democracy in the Digital Age. New York: Routledge Taylor Francis.

Wolak, Jennifer. 2014. "Candidate Gender and the Political Engagement of Women and Men." American Politics Research:: 1-25.

Wright, Scott. 2012. "Assessing (E-) Democratic innovations: 'Democratic Goods' and Downing Street E-Petitions." Journal of Information Technology \& Politics 9 (4): 453-470.

Xydias, Christina V. 2007. "Inviting More Women to the Party: Gender Quotas and Women's Substantive Representation in Germany." International Journal of Sociology 37 (4): 52-66.

Zipp, John F., and Eric Plutzer. 1985. "Gender Differences in Voting for Female Candidates: Evidence from the 1982 Election." Public Opinion Quarterly 49 (2): 179-197. 


\section{Appendix A: Change.org Petition Submission}

To help the reader understand the process of submitting a Change.org petition, we provide screenshots from each of the steps.

Figure 10: Petition Submission, First Step: Write a Petition Title

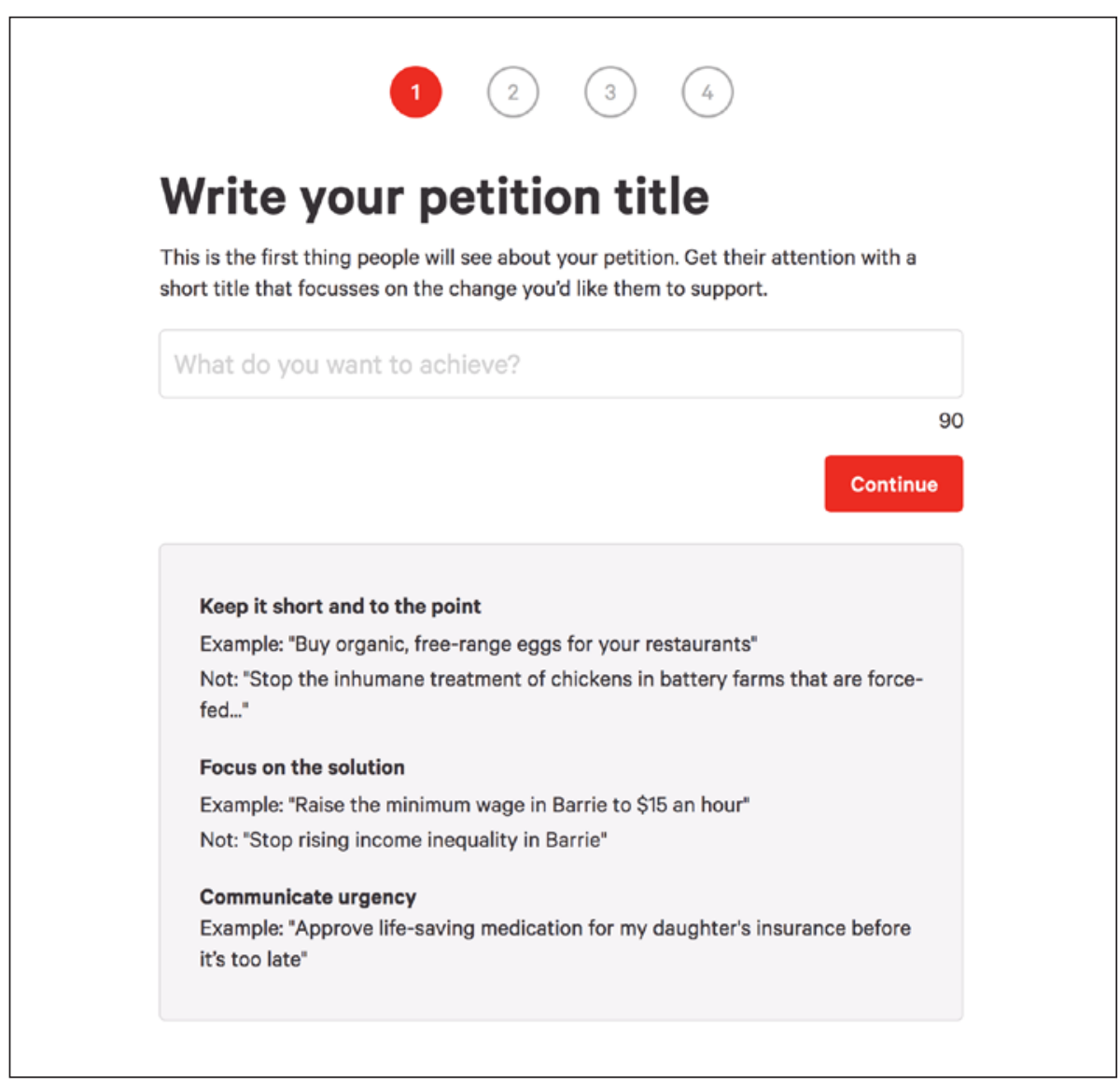


Gender and Political Mobilization Online

Figure 11: Petition Submission, Second Step: Choose a Target for the Petition

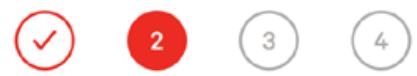

\section{Choose a decision maker}

This is the person, organisation, or group that can make a decision about your petition. Change.org will send them updates on your petition and encourage a response.

Who can make this happen?

Continue

Choose someone who can give you what you want

You might need to do some research to find the right person who can make or influence the decision.

Don't go straight to the top

You might see faster results if you choose a more junior person who is petitioned less often than more recognizable figures.

Choose someone you can work with

Your petition is most likely to win by reaching an agreement with your decision maker. 
Gender and Political Mobilization Online

Figure 12: Petition Submission, Third Step: Choose a Target for the Petition

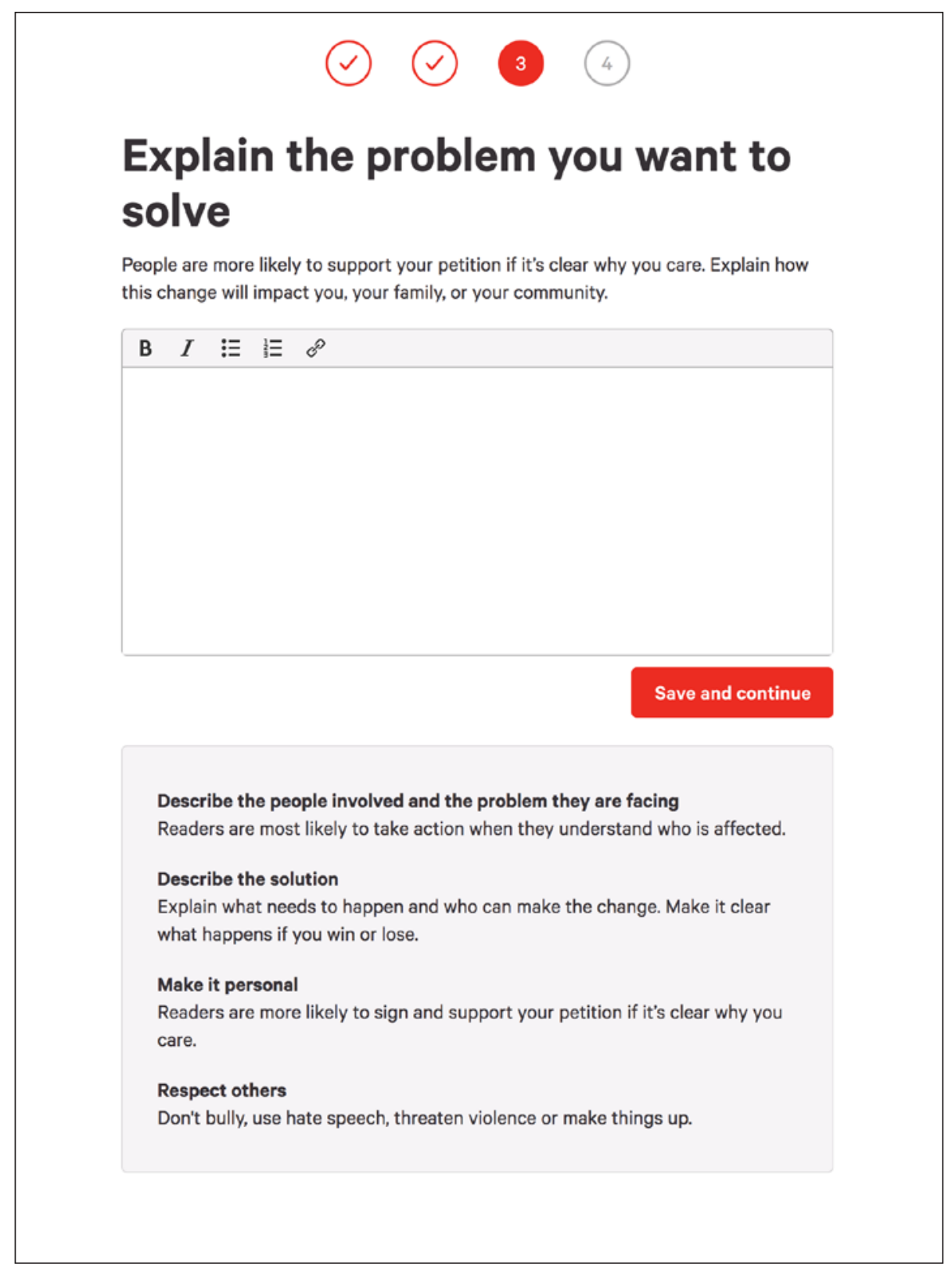


Figure 13: Petition Submission, Third Step (continued): Provide Information About the Petition Creator

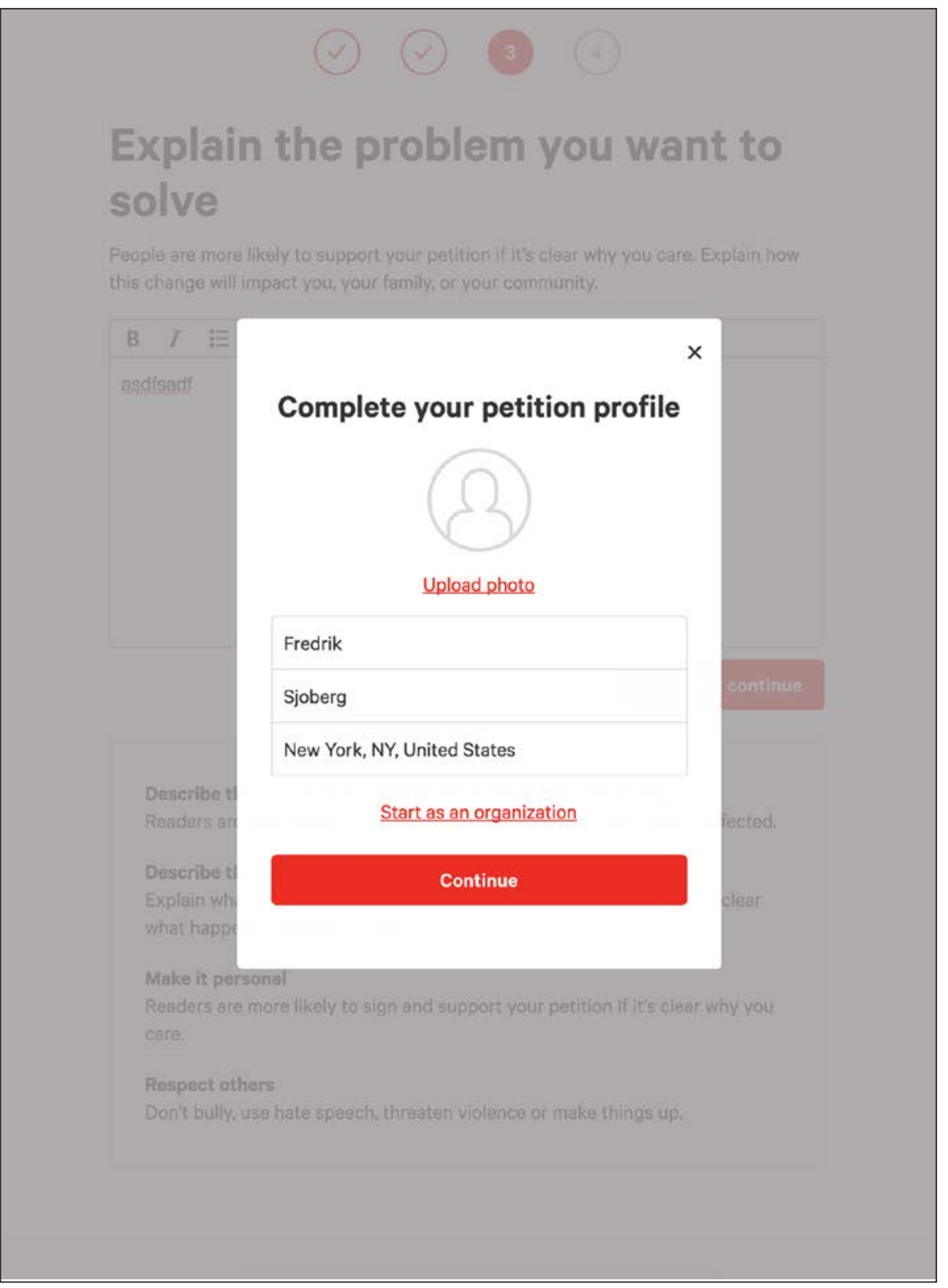


Figure 14: Petition Submission, Fourth Step: Add a Photo or a Video

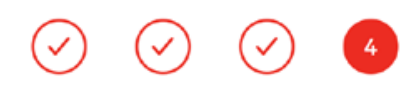

\section{Add a photo or video}

Petitions with a photo or video receive six times more signatures than those without. Include one that captures the emotion of your story.

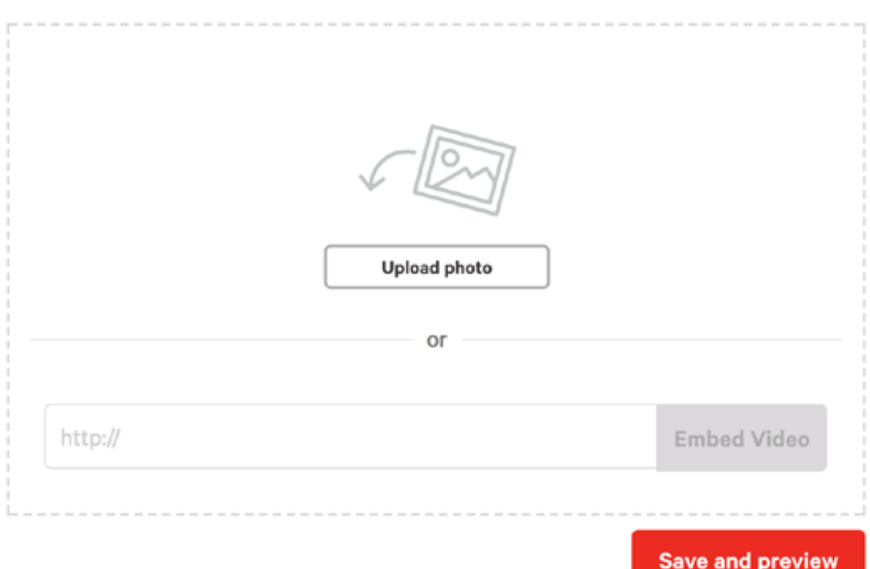

Choose a photo that captures the emotion of your petition Photos of people or animals work well.

Try to upload photos that are $1600 \times 900$ pixels or larger

Large photos look good on all screen sizes.

Keep it friendly for all audiences

Make sure your photo doesn't include graphic violence or sexual content. 


\section{Appendix B: Steps to Declare Victory}

After having submitted a petition, the creator can provide information about the success of the petition. Screenshots of the process are presented here.

Figure 15: Declaring Victory, First Step: Declare Victory

\section{Manage petition}

Did you come to an agreement with your decision maker? Declare your petition a victory and let your supporters know how they helped make it happen.

Declare victory Close petition

Figure 16: Declaring Victory, Second Step: Validation and Alternative Action Suggestions

\section{It looks like you might not be ready to declare victory yet}

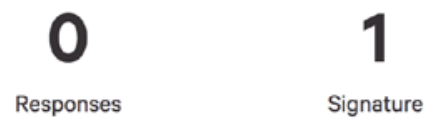

Petition starters achieve victory when their desired change happens, or when they come to an alternate agreement with the decision maker. Check out these guides to help your petition reach victory:

Promote your petition

Talk to your decision maker

Build a social media conversation 
Figure 17: Declaring Victory, Third Step: Request for More Information

\section{Congratulations!}

Let your supporters know you've reached your goal - they'll receive an email and an update will be added to your petition.

Write an update title

Victory!

Describe what happened

How did you reach your goal?

URL for an article, image, or video

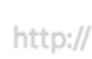

Add

or

Declare victory 


\section{Appendix C: Steps to Validate Victory}

Figure 18 shows the results of the manual success validation. The highly plausible cases are generally local issues, where there is limited news coverage (e.g., issuing a housing permit). Just $3 \%$ of petitions' claims were confirmed not to have happened or were coded as unlikely to have happened without evidence being present. The remaining claims were either unable to be confirmed either way or made ambiguous claims. These results suggest that outright lying is rare on Change.org petitions, but that there are a number of ambiguous cases. Nevertheless, the overall validation rate is high enough that we consider the victory variable to be broadly reliable (it has similar reliability to many survey recall measures, for instance).

Figure 18: Validation of Success Label Through Manual Coding of a Random Sample of Successful Petitions

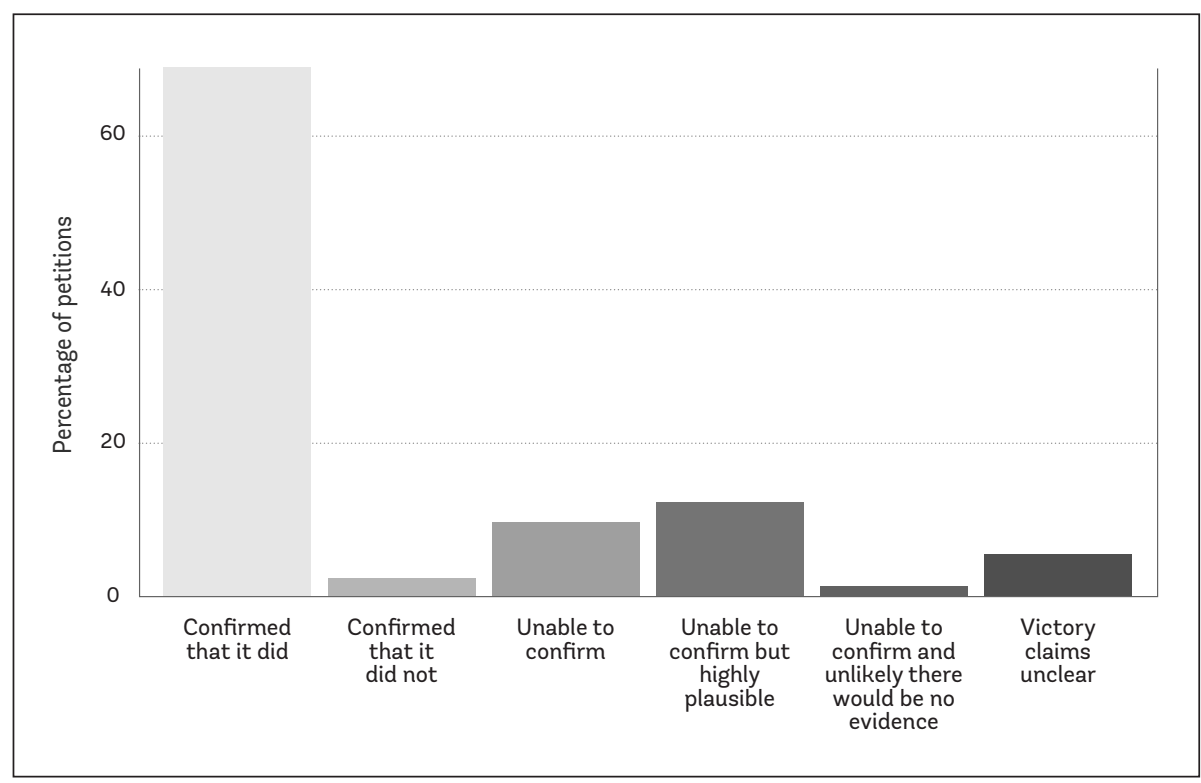

Note: Data is from a manual coding, by four different persons, of 296 successful petitions.

Finally, we also coded the type of change that the petition claimed to have achieved. The coders used a differentiated list of categories, but we combine them into five broad types in Figure 19. The results show that petitions overwhelmingly focus on concrete policy goals, either blocking policy, creating policy, or ending existing policy. Only $7 \%$ of petitions defined their success in terms of increased legitimacy, raising awareness, or changing attitudes. 
Figure 19: The Type of Change Successful Petitions Achieved, Manual Coding

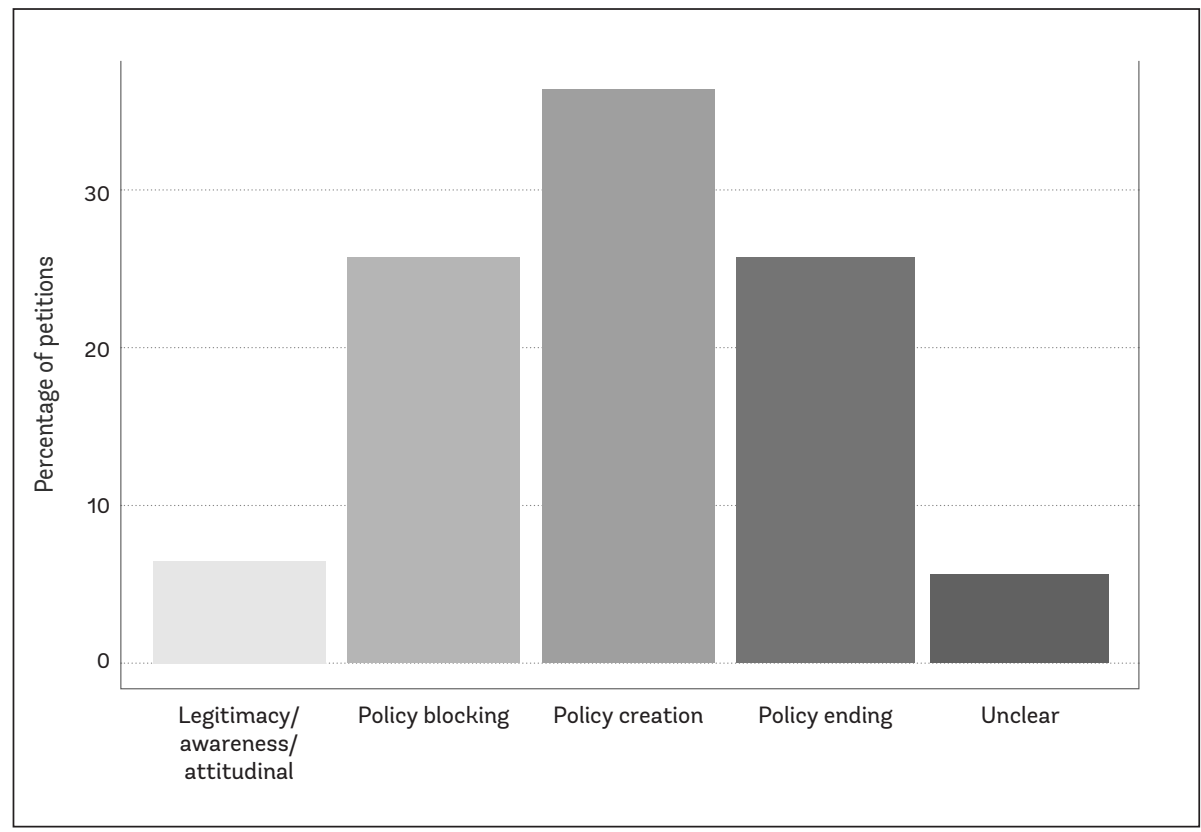

Note: Data is from a manual coding, by four different persons, of 296 successful petitions. 


\section{Appendix D: Spam Analysis}

Like many user platforms that rely on user contributions, Change.org has significant amounts of spam on the platform. This is not a problem from the perspective of analyzing the users, but is a potential concern when looking at the petitions themselves, which are often used as advertisements by spam companies. We take a heuristic approach to removing spam petitions using a series of rules derived iteratively from manually examining random samples of petitions. We use the following rules:

- Petitions with any of a series of common keywords (manually created) such as "download," "hair loss," "asdf," and "escorts"

- Petitions with fewer than 14 characters in the title

- Petitions with fewer than 25 characters in the title and one of a second set of keywords "convert|nothing|music|affiliate|song|crack|sing |play|petition|upload|listen"

- Petitions with more than four of the same letter repeated in the title, e.g., "ttttttt"

- Petitions with more than six consonants in a row in the title

- Petitions which exactly repeat the same phrase before and after a colon in the title

- Petitions with a keyword from the list "video|vedio|song|music" and the list "convert|convete|donwload|descargar|downold|downlowd"

- Petitions with fewer than eight unique characters in the title

- Petitions beginning with the word "test"

Using this approach, we flagged 119,645 petitions as spam (28.5\%). Spam petition creators skew somewhat more male than the rest of the sample $(68 \%$ male versus $55.9 \%$ in the rest of the sample). Spam petitions are far less likely to include a category ( $2.3 \%$ of petitions versus $23.8 \%$ in the rest of the sample). Spam petitions are also far less likely to be marked as successful (just 50 petitions out of 119,645). Most of these appear to be false positives. This contrasts with 3,603 successful petitions in the rest of the dataset. Spam petitions also receive many fewer signatures than other petitions. The mean number of signatures on spam petitions is just 9.2, compared with 336.5 on other petitions. Spam petitions are also much less likely to include a picture with their petition $(5.4 \%)$ than other petitions $(36.2 \%)$. 


\section{Appendix E: Simulation Analysis}

This appendix shows the simulated relationship between the overall success rate and the female level of descriptive success for different levels of issue and gender preference. The results show that higher levels of gender homophily (preference for signing petitions created by the same gender) makes descriptive success decline more slowly as the proportion of successes increases. Additionally, the strength of issue preference makes the curve more extreme at both ends. When issue preference is high, descriptive success more quickly reaches the level of thick participation as the overall success rate increases and more quickly reaches and even exceeds the level of thin participation as the overall success rate declines.

Figure 20: The Relationship Between Overall Success and Female Descriptive Success for Different Levels of Issue and Gender Preference
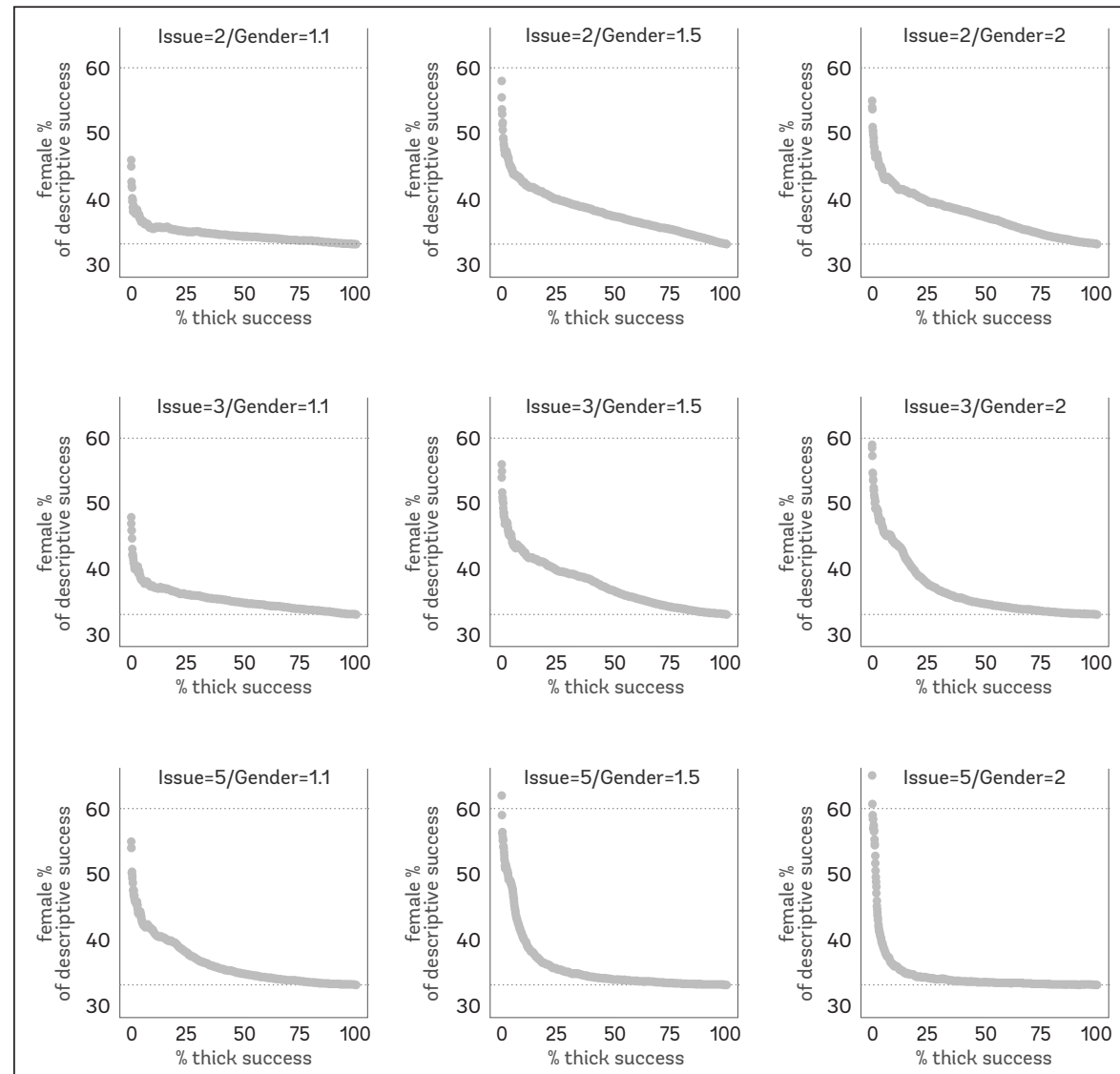

Note: The simulation code is available in an additional online appendix. 



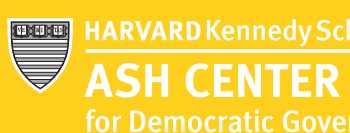

Is h Center for Democratic-
tavarard Kennedy School
9 J John F Kennedy Stree:

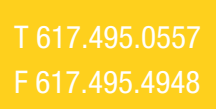

